\title{
Critical evaluation of the small punch test as a screening procedure for mechanical properties
}

\author{
E. Altstadt ${ }^{1 *}$, H.E. Ge ${ }^{2}$, V. Kuksenko ${ }^{2}$, M. Serrano ${ }^{3}$, M. Houska ${ }^{1}$, M. Lasan ${ }^{4}$, M. Bruchhausen ${ }^{5}$, \\ J.-M. Lapetite ${ }^{5}$, Y. Dai ${ }^{2}$ \\ ${ }^{1}$ Helmholtz-Zentrum Dresden - Rossendorf (HZDR), Dresden, Germany \\ ${ }^{2}$ Paul-Scherrer-Institut, Villigen, Switzerland \\ ${ }^{3}$ Centro de Investigaciones Energéticas, Medioambientales y Tecnológicas (CIEMAT), Madrid, Spain \\ ${ }^{4}$ Research Centre Rez (RCR), Husinec, Czech Republic \\ ${ }^{5}$ Joint Research Centre, Institute of Energy and Transport (JRC-IET), Petten, Netherlands \\ * Corresponding author: e.altstadt@hzdr.de, +49-351-2602276, D-01328 Dresden, Bautzner Landstrasse 400
}

\begin{abstract}
Within a collective exercise, a systematic and statistically based analysis of the repeatability and device dependence of small punch test results was performed. An unirradiated ferriticmartensitic steel T91 was selected for this. The test results allowed an evaluation of accuracy and reliability of material properties extracted from load-displacement-based and energybased parameters. In a second step, neutron irradiated T91 with doses of 2.3 and 4 dpa was investigated in the temperature range $-165^{\circ} \mathrm{C}$ to $300{ }^{\circ} \mathrm{C}$. The effects of test temperature and irradiation on the load-displacement curves and on the derived parameters were analysed. It was found that the small punch test is well suited for estimation of neutron embrittlement in cases of small amounts of available material or high activity. The preferred procedure for that purpose was specified.
\end{abstract}

\section{Introduction}

Small specimen test technologies have long been recognized as a supportive means for the development and monitoring of structural materials for nuclear components [1]. The small punch (SP) test [2-11] received much attraction and widespread use. However, details of the sample preparation, device and sample geometry as well as testing procedure and analysis may differ from laboratory to laboratory. Within the Euratom FP7-Project MATTER (MATerials TEsting and Rules), work package 2 was dedicated to the development of screening test procedures for mechanical properties. Screening procedures are intended to provide approximate data of the properties with as small amounts of material as possible and thus allowing a quick evaluation of ageing mechanisms such as neutron irradiation induced hardening and embrittlement or liquid metal embrittlement. Amongst others, the SP test was selected as a testing method for screening.

The SP test is well suited to investigate irradiation effects, since the amount of material needed is small and thereby the total activity of specimens is much lower than for classical mechanical and fracture mechanics tests. For example the mass and thus the activity ratio between a SP standard specimen $\left(\varnothing 8 \times 0.5 \mathrm{~mm}^{3}\right)$ and a full-sized Charpy specimen $\left(10 \times 10 \times 55 \mathrm{~mm}^{3}\right)$ is approximately $1: 220$.

The ductile to brittle transition temperature (DBTT) can be extracted from the SP tests. From a single load-deflection curve one can calculate the energy $E_{S P}$ needed to deform and crack the SP sample. Doing this for different temperatures, the $\mathrm{E}_{\mathrm{SP}}(\mathrm{T})$ curve can be constructed. Usually this curve is assembled from two fits, the first one describing the brittle and transition regime and the second one the ductile regime. The intersection of the two curves marks the maximum of the fitted $\mathrm{E}_{\mathrm{SP}}(\mathrm{T})$ course, $\mathrm{E}_{\max }$. The $\mathrm{SP}$ transition temperature $\mathrm{T}_{\mathrm{SP}}$ is defined as temperature where $\mathrm{E}_{\mathrm{SP}}=0.5^{*}\left(\mathrm{E}_{\max }-\mathrm{E}_{\min }\right)$ holds [2,3]. A linear correlation with the Charpy transition temperature $\mathrm{T}_{\mathrm{CVN}}$ is proposed in $[4,5]$ : 


$$
\mathrm{T}_{\mathrm{SP}}=\alpha \cdot \mathrm{T}_{\mathrm{CVN}}
$$

where absolute temperatures have to be used. The factor $\alpha$ was found to be $0.32 \ldots 0.34$ for 2.25Cr-1Mo steels and $1 \mathrm{Cr}-0.5 \mathrm{Mo}$ steels respectively, based on SP specimens of $0.5 \mathrm{~mm}$ thickness and a punch ball diameter of $2.4 \mathrm{~mm}$. However, other results [6,7] give rise to the assumption that the factor $\alpha$ depends on both the SP geometry and the material. Kameda provided a rationale for the linear relationship Eq. (1) by means of a kinetic model for ductilebrittle fracture mode transition considering also the strain rate effect [8]:

$$
\alpha=\frac{\mathrm{T}_{\mathrm{SP}}}{\mathrm{T}_{\mathrm{CVN}}}=\frac{\left\{\ln \left[\left(\frac{\mathrm{V}_{\mathrm{S}} \mathrm{F}_{\mathrm{S}}}{\mathrm{V}_{\mathrm{t}} \mathrm{F}_{\mathrm{t}}}\right)\left(\frac{\dot{\varepsilon}_{0}}{\dot{\varepsilon}}\right)^{2}\right]\right\}_{\mathrm{CVN}}}{\left\{\ln \left[\left(\frac{\mathrm{V}_{\mathrm{S}} \mathrm{F}_{\mathrm{S}}}{\mathrm{V}_{\mathrm{t}} \mathrm{F}_{\mathrm{t}}}\right)\left(\frac{\dot{\varepsilon}_{0}}{\dot{\varepsilon}}\right)^{2}\right]\right\}_{\mathrm{SP}}}
$$

where $\mathrm{V}$ and $\mathrm{F}$ are fracture volume and micro-crack density respectively, and the subscripts $\mathrm{s}$ and $t$ indicate shear and tension. Based on results for ferritic-martensitic steels, the factor was obtained as $\alpha \approx 0.4$.

The SP test has also been used to estimate hardening, i.e. increase of the yield stress (YS). A linear correlation was proposed for the YS

$$
\mathrm{R}_{\mathrm{p} 02}=\beta_{\mathrm{YS}} \cdot \mathrm{F}_{\mathrm{e}} / \mathrm{h}^{2}
$$

with $\mathrm{h}$ being the initial specimen thickness, $\mathrm{F}_{\mathrm{e}}$ the SP load at the onset of plastic flow and $\beta_{\mathrm{YS}}$ an empirical factor. Kameda and Mao [9] found $\beta_{Y S}=0.36$ for specimen thicknesses of $0.25 \mathrm{~mm}$ and $0.5 \mathrm{~mm}$. In [10] the correlation was underpinned by finite element simulations of SP tests. Two different correlations were proposed for the estimation of the ultimate tensile strength (UTS) [10,11]:

$$
\begin{aligned}
& \mathrm{R}_{\mathrm{m}}=\beta_{\mathrm{UTS}} \cdot \mathrm{F}_{\mathrm{m}} / \mathrm{h}^{2} \\
& \mathrm{R}_{\mathrm{m}}=\beta_{\mathrm{UTS}} \cdot \mathrm{F}_{\mathrm{m}} /\left(\mathrm{h} \cdot \mathrm{u}_{\mathrm{m}}\right)
\end{aligned}
$$

with $\mathrm{F}_{\mathrm{m}}$ being the maximum load and $\mathrm{u}_{\mathrm{m}}$ the corresponding displacement.

Detailed analyses of stress and strain in the SP disc have been performed by means of analytical elastic-plastic modelling [12,13] and by finite element calculations [10,14,15]. A combination of finite element modelling, SP testing and neural networks was used to identify the parameters of the Gurson-Tvergaard-Needleman model for ductile damage [14] and of the Beremin model for brittle fracture [15].

In this paper, we present the results of a SP test collective exercise with unirradiated T91 steel. This exercise aimed at the analysis of scatter, reproducibility and device dependence of characteristic parameters extracted from SP tests. 
Another focus of the paper is put on the investigation of neutron irradiation induced hardening and embrittlement by means of the SP test. The usefulness of the above mentioned correlations for screening of hardening and embrittlement (Eqs. 1-4) is evaluated.

\section{Material}

All tests reported in this paper are related to the $9 \mathrm{Cr}$ ferritic martensitic steel $\mathrm{T} 91$ as defined in the ASTM standard A387-Ed99 (Grade 91 Class 2 / S50460). Two heats of this material were investigated. The first heat was characterised in the FP6 project EUROTRANS (project domain 4 - DEMETRA). This heat was produced by ARCELOR and is referred to as "T91-DEM" in this paper. It was used for the SP collective exercise. The second heat was produced by UGINE, France. It was characterised within the FP5 project SPIRE. This heat is referred to as "T91-SPI" in this paper. A neutron irradiation experiment at the reactor BR2 in Mol, Belgium, was part of the SPIRE project. The T91-SPI heat was used for the evaluation of irradiation induced hardening and embrittlement. The chemical compositions are listed in Table 1 and heat treatments and product forms in Table 2.

Table 1: Composition the T91 heats (wt\%)

\begin{tabular}{llllllllllllllll}
\hline & $\mathrm{C}$ & $\mathrm{Si}$ & $\mathrm{V}$ & $\mathrm{Cr}$ & $\mathrm{Mn}$ & $\mathrm{Ni}$ & $\mathrm{Mo}$ & $\mathrm{N}$ & $\mathrm{Al}$ & $\mathrm{P}$ & $\mathrm{S}$ & $\mathrm{Ti}$ & $\mathrm{Cu}$ & $\mathrm{Nb}$ & $\mathrm{W}$ \\
\hline T91-DEM & 0.1025 & 0.22 & 0.21 & 8.99 & 0.38 & 0.11 & 0.89 & 0.0442 & 0.0146 & 0.021 & 0.0004 & 0.0034 & 0.06 & 0.06 & 0.01 \\
\hline T91-SPI & 0.099 & 0.32 & 0.24 & 8.8 & 0.43 & 0.24 & 0.96 & 0.03 & $<0.01$ & 0.02 & 0.004 & $<0.005$ & 0.05 & 0.06 & $<0.01$ \\
\hline
\end{tabular}

Table 2: Product form and heat treatment

\begin{tabular}{lll}
\hline Heat & Product form & Heat treatment \\
\hline T91-DEM & $\begin{array}{l}\text { hot rolled plate } \\
\text { thickness } 15 \mathrm{~mm}\end{array}$ & $\begin{array}{l}\text { normalization } 1050^{\circ} \mathrm{C} / 15 \mathrm{~min} \\
\text { tempering } 770{ }^{\circ} \mathrm{C} / 45 \mathrm{~min}\end{array}$ \\
\hline T91-SPI & $\begin{array}{l}\text { hot rolled plate } \\
\text { thickness } 15 \mathrm{~mm}\end{array}$ & $\begin{array}{l}\text { normalization } 1040{ }^{\circ} \mathrm{C} / 60 \mathrm{~min} \\
\text { tempering } 760{ }^{\circ} \mathrm{C} / 60 \mathrm{~min}\end{array}$ \\
\hline
\end{tabular}

The temperature dependent yield stress and tensile strength are shown in Figure 1 (T91-DEM) Figure 2 (T91-SPI). The data were taken from [16] and [17] respectively. The temperature fits for $\mathrm{R}_{\mathrm{p} 02}$ and $\mathrm{R}_{\mathrm{m}}$ of T91-DEM are given by Eq. (5):

$$
\begin{aligned}
& \mathrm{R}_{\mathrm{p} 02}(\mathrm{MPa})=588-0.165 \cdot \mathrm{T}(\mathrm{K})+1248 \cdot \exp [-0.013 \cdot \mathrm{T}(\mathrm{K})] \\
& \mathrm{R}_{\mathrm{m}}(\mathrm{MPa})=713-0.205 \cdot \mathrm{T}(\mathrm{K})+995 \cdot \exp [-0.011 \cdot \mathrm{T}(\mathrm{K})]
\end{aligned}
$$

For T91-SPI the temperature fits are given by Eq. (6):

$$
\begin{aligned}
& \mathrm{R}_{\mathrm{p} 02}(\mathrm{MPa})=602-0.241 \cdot \mathrm{T}(\mathrm{K})+51633 \cdot \exp [-0.05 \cdot \mathrm{T}(\mathrm{K})] \\
& \mathrm{R}_{\mathrm{m}}(\mathrm{MPa})=794-0.398 \cdot \mathrm{T}(\mathrm{K})+43321 \cdot \exp [-0.05 \cdot \mathrm{T}(\mathrm{K})]
\end{aligned}
$$

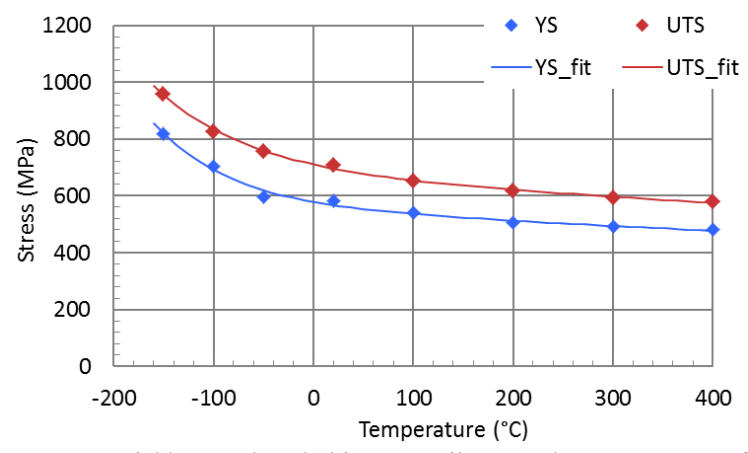

Figure 1: Yield strength and ultimate tensile strength vs. temperature for T91-DEM [16] 


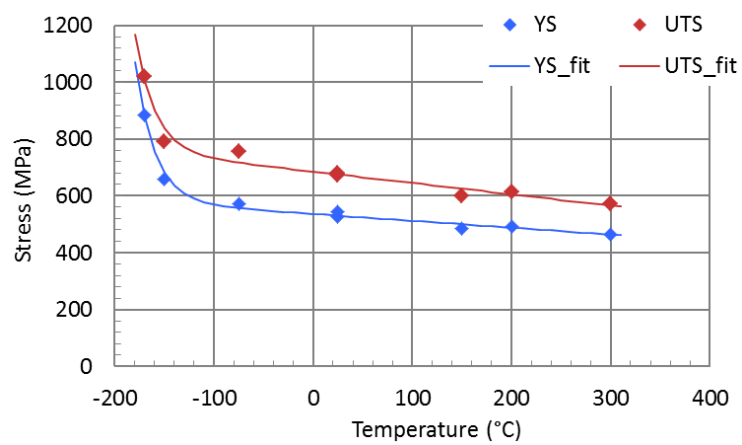

Figure 2: Yield strength and ultimate tensile strength vs. temperature for T91-SPI [17]

For T91-SPI, tensile tests results at $200{ }^{\circ} \mathrm{C}$ of the unirradiated and neutron irradiated conditions are given in Table 3 [17].

Table 3: Tensile properties of T91-SPI at $\mathbf{2 0 0}^{\circ} \mathbf{C}$ for different irradiation conditions [17]
\begin{tabular}{llllll}
\hline $\begin{array}{l}\text { Dose } \\
(\mathrm{dpa})\end{array}$ & $\begin{array}{l}\text { Yield stress, } \mathrm{R}_{\mathrm{p} 02} \\
(\mathrm{MPa})\end{array}$ & $\begin{array}{l}\text { UTS, } \mathrm{R}_{\mathrm{m}} \\
(\mathrm{MPa})\end{array}$ & $\begin{array}{l}\text { Uniform strain } \\
(\%)\end{array}$ & $\begin{array}{l}\text { Fracture strain } \\
(\%)\end{array}$ & $\begin{array}{l}\text { area reduction, } \\
(\%)\end{array}$ \\
\hline 0 & 494 & 616 & 6 & 19 & 72 \\
\hline 2.95 & 835 & 838 & 2 & 12 & 79 \\
\hline 4.36 & 835 & 840 & 2 & 11 & 65 \\
\hline
\end{tabular}

The ductile to brittle transition temperatures obtained by means of KLST specimens are listed in Table 4. There was no significant anisotropy $[16,17]$. According to a work of Klausnitzer [18] the ductile-to-brittle transition temperature obtained from KLST tests ( $\mathrm{T}_{\mathrm{KLST}}$ ) can be converted into standard transition temperatures obtained by Charpy specimens $\left(\mathrm{T}_{\mathrm{CVN}}\right)$ by the following correlation:

$$
\mathrm{T}_{\mathrm{CVN}}=\mathrm{T}_{\mathrm{KLST}}+65 \mathrm{~K}
$$

Table 4: Ductile to brittle transition temperatures of T91-DEM [15] and T91-SPI [17]

\begin{tabular}{lcccc}
\hline Heat & Dose $(d p a)$ & USE $(J)$ & $\mathrm{T}_{\mathrm{KLST}}\left({ }^{\circ} \mathrm{C}\right)$ & $\mathrm{T}_{\mathrm{CVN}}\left({ }^{\circ} \mathrm{C}\right), \mathrm{Eq} .(7)$ \\
\hline T91-DEM & 0 & 8.7 & -98 & -33 \\
\hline T91-SPI & 0 & 6.5 & -73 & -8 \\
\hline T91-SPI & 2.43 & 6.0 & 35 & +100 \\
\hline T91-SPI & 3.58 & 6.1 & 57 & +122 \\
\hline
\end{tabular}

\section{Experimental}

\subsection{SP test collective exercise}

Five laboratories (labelled as Lab1 to Lab5) participated in the collective exercise. The heat T91-DEM was used for this exercise. Two basic geometries were considered for the manufacturing of the SP specimens: small geometry (specimen thickness $0.25 \mathrm{~mm}$ ) and standard geometry (specimen thickness $0.5 \mathrm{~mm}$ ). Further geometrical details are summarized in Figure 3 and Table 5. The specimen is assumed to be fully clamped so that the outer contour of the specimens (square or round) has no effect. The test devices of the different labs for the standard geometry have basically the same dimensions. Only the lower die edge is differently shaped (edge radius $0.5 \mathrm{~mm}$ vs. chamfer $0.2 \mathrm{~mm} \times 45^{\circ}$ ). For the small geometry, there are additionally differences in the lower die diameter. 


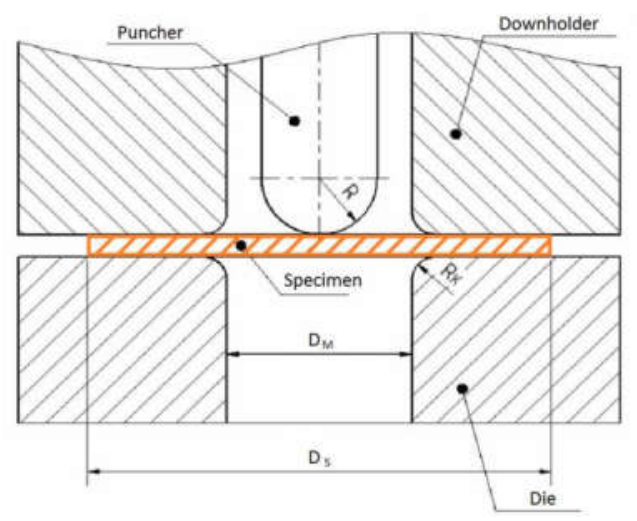

Figure 3: SP test geometry

\begin{tabular}{lll}
\multicolumn{2}{l}{ Table 5: Main geometrical parameters of the test devices and specimens } \\
\hline \multicolumn{1}{l}{ Small geometry } & Standard geometry \\
\hline Specimen thickness $\mathrm{h}(\mathrm{mm})$ & 0.25 & 0.5 \\
\hline Lower die diameter $\mathrm{D}_{\mathrm{M}}(\mathrm{mm})$ & $1.75(\mathrm{Lab} 2), 1.5(\mathrm{Lab} 1, \mathrm{Lab} 3)$ & 4.0 \\
\hline \multirow{2}{*}{ Edge radius $\mathrm{R}_{\mathrm{K}}(\mathrm{mm})$ or chamfer } & $0.2(\mathrm{Lab} 1), 0.25(\mathrm{Lab} 2)$, & $0.2(\mathrm{Lab} 1), 0.5(\mathrm{Lab} 2)$, \\
& $0.2 \times 45^{\circ}(\mathrm{Lab} 3)$ & $0.2 \times 45^{\circ}(\mathrm{Lab3}, \mathrm{Lab} 4, \mathrm{Lab} 5)$ \\
\hline Puncher radius $\mathrm{R}(\mathrm{mm})$ & 0.5 & 1.25 \\
\hline \multirow{2}{*}{ Specimen size, $\mathrm{mm}$} & $\varnothing 3 \times 0.25(\mathrm{Lab} 1, \mathrm{Lab} 3)$ & $\varnothing 8 \times 0.5(\mathrm{all}$ but Lab2) \\
& $3.5 \times 3.5 \times 0.25(\mathrm{Lab} 2)$ & $10 \times 10 \times 0.5(\mathrm{Lab} 2)$ \\
\hline
\end{tabular}

The specimens were cut to a thickness of $0.4 \mathrm{~mm}$ (small geometry) or $0.6 \mathrm{~mm}$ (standard geometry) respectively by means of electrical discharge machines (EDM) and subsequent ground with grit 1200 to final thickness. The individual final thickness of each specimen was protocolled in the test reports of the labs. The maximum accepted thickness tolerance was $0.5 \%$ of the nominal thickness [5]. All tests were performed at a displacement rate of $0.3 \mathrm{~mm} / \mathrm{min}$. The requested tolerance for the measurement of the test temperature was $\pm 3 \mathrm{~K}$.

Five tests were performed at RT and five tests at $300{ }^{\circ} \mathrm{C}$ for both geometries. For each of the two temperature levels an average load-displacement curve was to be calculated including the scatter band. Additional tests were performed in the temperature range $-195 \ldots 20^{\circ} \mathrm{C}$ for the evaluation of the DBTT. In total, each lab conducted between 24 and 55 SP tests per geometry. Three of the labs (Lab1, Lab2 and Lab3) conducted tests for both geometries while the others conducted the tests for the standard geometry only.

The YS and UTS are estimated by means of Eqs. (2) and (3). The transition load $\mathrm{F}_{\mathrm{e}}$ is determined by a bilinear fit procedure according to code of practice [5], cf. Figure 4 . We used $\mathrm{u}_{\mathrm{B}}=0.5 \mathrm{~mm}$ for the standard geometry and $\mathrm{u}_{\mathrm{B}}=0.2 \mathrm{~mm}$ for the small geometry. The parameter $\mathrm{u}_{\mathrm{A}}$ was optimized in such a way that the sum of square errors of both regression lines is minimized.

In order to estimate the coefficient $\beta_{\mathrm{YS}}$, the values of $\mathrm{F}_{\mathrm{e}} / \mathrm{h}^{2}$ were plotted against the YS calculated by Eq. (5a) for the according test temperature. As an example the plot of Lab2 for the standard geometry is shown in Figure 5. Likewise the UTS obtained from Eq. (5b) and the values $F_{m} /\left(h \cdot u_{m}\right)$ or $F_{m} / h^{2}$ respectively were used to obtain the coefficient $\beta_{U T S}$. 

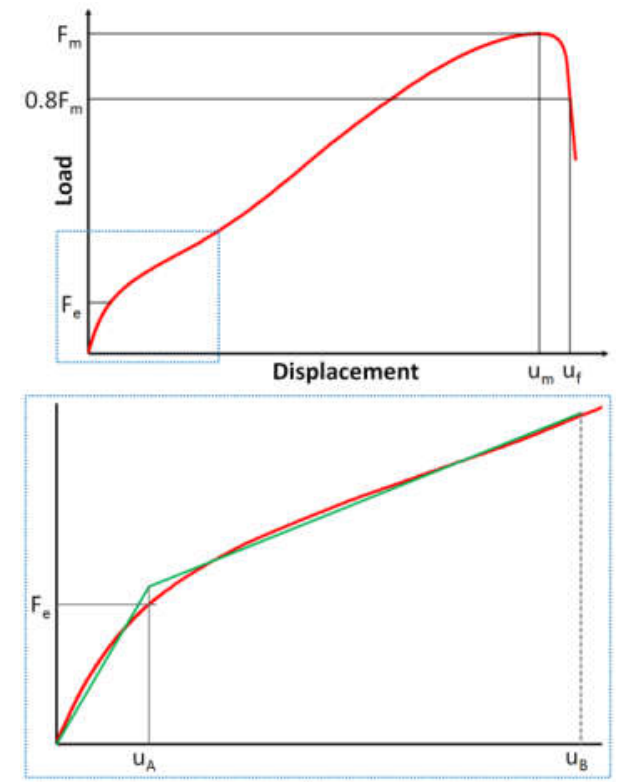

Figure 4: Characteristic parameters of the SP load-displacement curve [5]

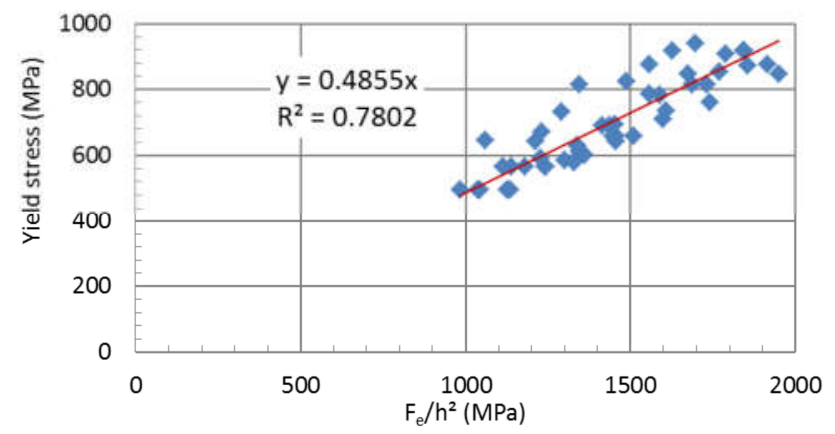

Figure 5: Regression line between $R_{p 02}$ and $F_{e} / h^{2} ; 10 \times 10 \times 0.5$ samples, Lab2, T91-DEM

The ductile to brittle transition temperature was evaluated from the temperature dependent SP energies. The total SP energy is the area under the load displacement curve. The energy up to the displacement at maximum load $\mathrm{u}_{\mathrm{m}}$ was used. The plastic energy is calculated by:

$$
\mathrm{E}_{\mathrm{SP}, \mathrm{pl}}=\mathrm{E}_{\mathrm{SP}, \mathrm{to}}-0.5 \cdot \mathrm{F}_{\mathrm{m}}^{2} \cdot \mathrm{u}_{\mathrm{A}} / \mathrm{F}_{\mathrm{A}}
$$

where $\left(\mathrm{u}_{\mathrm{A}}, \mathrm{F}_{\mathrm{A}}\right)$ is the intersection point of the bilinear fit for the determination of $\mathrm{F}_{\mathrm{e}}(\mathrm{cf}$. Figure 4).

A two-curve fitting procedure was applied for the $\mathrm{E}_{\mathrm{SP}}(\mathrm{T})$ dependence. The fitting curves are both described by the following exponential equation:

$$
E_{b / d}(T)=A_{b / d}+B_{b / d} \cdot \exp \left[C_{b / d} \cdot T\right]
$$

where the index " $b$ " refers to the brittle region and the index " $d$ " to the ductile region. The absolute temperature is used. A least square procedure was used to determine the coefficients $A_{b}, B_{b}, C_{b}, A_{d}, B_{d}$, and $C_{d}$. The intersection of the two curves marks the maximum of the fitted $E_{S P}(T)$ dependency, $E_{\max }$, while the minimum energy is given by $E_{\min }=A_{b}+B_{b}$ (i.e. $\mathrm{T}=0 \mathrm{~K})$. The SP transition temperature $\mathrm{T}_{\mathrm{SP}}$ is defined as temperature where 
$E_{b}\left(T_{S P}\right)=\left(E_{\min }+E_{\max }\right) / 2$ holds. As an example, Figure 6 shows the $E_{S P}(T)$ plot of Lab2 for the standard geometry.

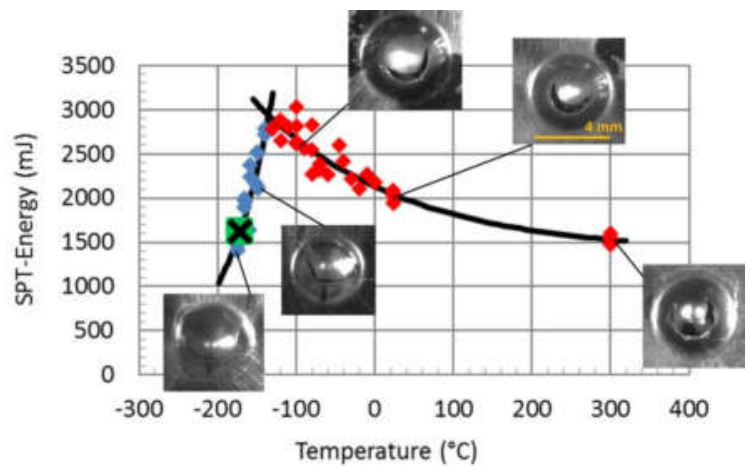

Figure 6: Determination of $T_{\mathrm{SP}}$ using the total energy up $u_{\mathrm{m}}$, T91-DEM, Lab2, standard geometry, $\mathrm{T}_{\mathrm{SP}}=-172{ }^{\circ} \mathrm{C}(\mathrm{black} \mathrm{X})$

The different fracture modes are also shown. One circular crack occurs during ductile failure whilst the brittle failure is characterised by several edged cracks. Other authors used the macroscopic appearance of the cracks as an additional screening criterion for ductility of the material $[19,20]$.

\subsection{SP tests for the evaluation of irradiation effects}

Unirradiated broken Charpy samples of the T91-SPI heat and neutron irradiated broken KLST samples of this material were employed for the manufacturing of the SP samples (cf. Table 6).

Table 6: Specimen codes and irradiation conditions of broken Charpy and KLST specimens used for the manufacturing of SP test samples

\begin{tabular}{|c|c|c|c|c|}
\hline Specimen code & Specimen type & Neutron dose (dpa) & $\begin{array}{l}\text { Irradiation temperature } \\
\left({ }^{\circ} \mathrm{C}\right)\end{array}$ & Codes of SP specimens \\
\hline T91-17 & Charpy & 0 & - & $01,02, \ldots, 39$ \\
\hline KR (one half) & KLST & 2.31 & 200 & KR01 ... KR11 \\
\hline KS (both halves) & KLST & 2.31 & 200 & KS01 ... KS22 \\
\hline MA (one half) & KLST & 2.31 & 200 & MA01 ... MA11 \\
\hline HE (both halves) & KLST & 3.99 & 200 & HE01 ... HE21 \\
\hline HH (both halves) & KLST & 3.99 & 200 & HH01 ... HH21 \\
\hline
\end{tabular}

The neutron irradiation had been performed in the framework of the SPIRE project [17]. The material was irradiated at $(200 \pm 5)^{\circ} \mathrm{C}$ in the $\mathrm{BR} 2$ reactor (Mol, Belgium) using the MISTRAL irradiation rig for 6 cycles.

The specimen geometry for the SP tests is $4 \times 3 \times 0.3 \mathrm{~mm}^{3}$. Slices from the KLST specimens were taken by EDM in a hot cell. The samples were not ground or polished. To improve the surface quality, a post cut was applied. A total number of 39 specimens were manufactured from the unirradiated material and 76 specimens from the irradiated material. The test temperatures ranged from $-165^{\circ} \mathrm{C}$ to $+303{ }^{\circ} \mathrm{C}$. All tests including those for the unirradiated condition were performed in the hot cell laboratory of Lab2 in order to exclude any effects from the testing device when evaluating the irradiation effect. As an example selected loaddisplacements curves of the neutron dose 2.31 dpa are shown in Figure 7. 


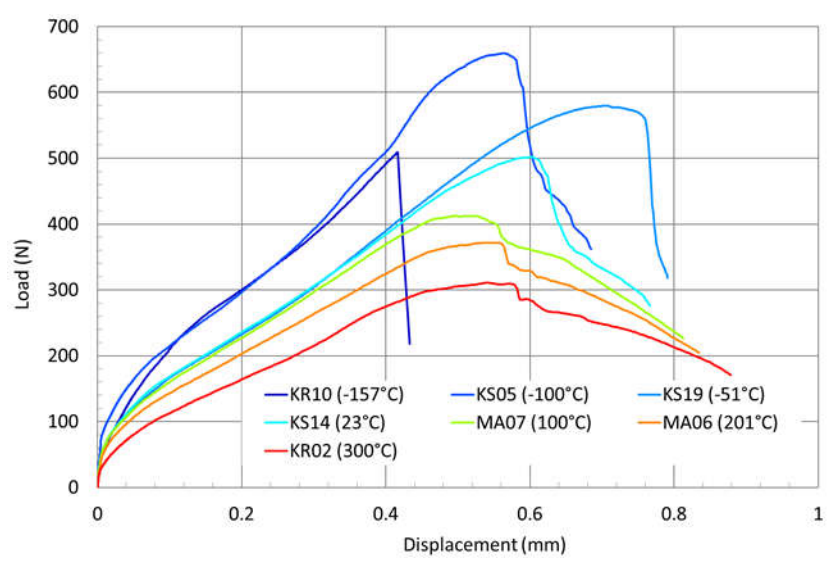

Figure 7: Load-displacement curves at selected temperatures, 4 × 3 x 0.3, T91-SPI, 2.31 dpa

\section{Results}

\subsection{SP test collective exercise}

As a first step, we compare the load-displacement curves of different labs in order to evaluate the effect of the individual test devices. Figure 8 shows the mean curves out of five tests at $300{ }^{\circ} \mathrm{C}$. The averaging procedure includes the following steps: i) normalisation of the loads and displacements to the range $[0,1]$ for each data series; ii) calculate the normalised path lengths of the data points for each series; iii) calculate the arithmetic mean of the data points which have the same relative paths length; iv) apply steps $\mathrm{i}-$ iii for the displacement ranges $\left[0, \mathrm{u}_{\mathrm{m}}\right]$ and $\left[\mathrm{u}_{\mathrm{m}}, \mathrm{u}_{\mathrm{f}}\right]$ section by section.

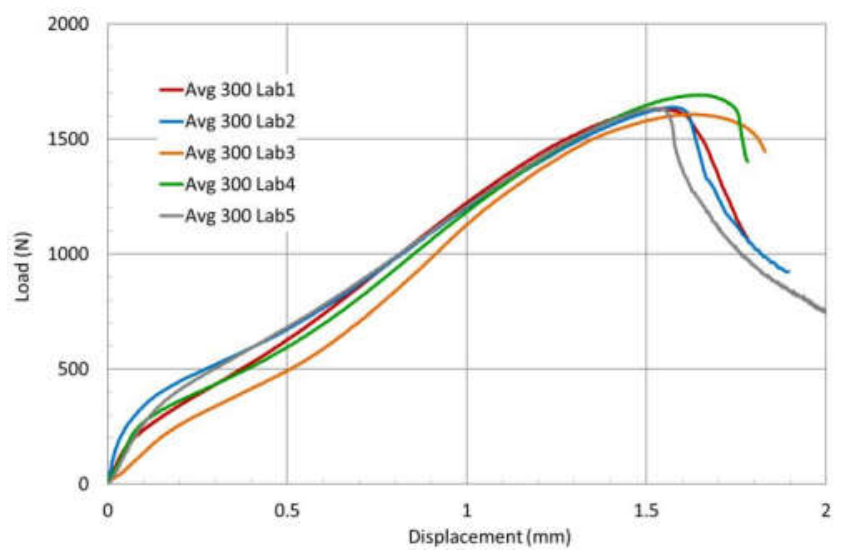

Figure 8: Comparison of load-displacement curves of tests at $300{ }^{\circ} \mathrm{C}$; averaged curves out of 5 tests; T91-DEM specimen thickness $0.5 \mathrm{~mm}$

While the maximum loads are in a quite good agreement, the curves differ in the slope of the elastic part. This results also in significant differences in the range up to $1 \mathrm{~mm}$ displacement. The displacements $\mathrm{u}_{\mathrm{m}}$ at maximum load agree reasonably. A detailed analysis of the SP results is given in Table 7 for room temperature and in Table 8 for $\mathrm{T}=300{ }^{\circ} \mathrm{C}$. The mean values $\mu$ of the parameters $\mathrm{E}_{\mathrm{to}}, \mathrm{E}_{\mathrm{pl}}, \mathrm{F}_{\mathrm{e}}, \mathrm{F}_{\mathrm{m}}$ and $\mathrm{u}_{\mathrm{m}}$ were calculated from the five individual tests for each lab. The relative error for the parameters is expressed by means of the coefficient of variation, i.e. the ratio of standard deviation $\sigma$ and mean $\mu\left(c_{v}=\sigma / \mu\right)$. The values in the last row ("All labs") were calculated from the mean values $\mu$ of Lab1 to Lab5. Thus, the average $c_{v}$ is not the arithmetic mean of the $c_{v}$ values of the labs. The $c_{v}$-values of Lab1 - Lab5 indicate the in-house repeatability of the parameters using one and the same SP device, while the $\mathrm{c}_{\mathrm{v}}$-values in the "All labs" row characterise the inter-laboratory reproducibility (i.e. the effect of different devices) on the parameters. Low $\mathrm{c}_{\mathrm{v}}$-values indicate a good repeatability and 
a low device dependence (good reproducibility) respectively. It should be noted, that the main geometrical parameters of the different SP test set-ups are identical (Table 5), some minor differences like chamfer and edge radius of the lower die hole or the outer shape of the specimen are not believed to cause significant differences in the SP results.

Table 7: Mean value $\mu$ and coefficient of variation $c_{v}$ of results of SP tests at room temperature, standard geometry

\begin{tabular}{|c|c|c|c|c|c|c|c|c|c|c|}
\hline & \multicolumn{2}{|c|}{$\mathrm{E}_{\text {to }}$ up to $\mathrm{u}_{\mathrm{m}}$} & \multicolumn{2}{|c|}{$\mathrm{E}_{\mathrm{pl}}$ up to $\mathrm{u}_{\mathrm{m}}$} & \multicolumn{2}{|c|}{$\mathrm{F}_{\mathrm{e}}$} & \multicolumn{2}{|c|}{$\mathrm{F}_{\mathrm{m}}$} & \multicolumn{2}{|c|}{$\mathrm{u}_{\mathrm{m}}$} \\
\hline & $\mu(\mathrm{mJ})$ & $\mathrm{c}_{\mathrm{v}}(\%)$ & $\mu(\mathrm{mJ})$ & $\mathrm{c}_{\mathrm{v}}(\%)$ & $\mu(\mathrm{N})$ & $\mathrm{c}_{\mathrm{v}}(\%)$ & $\mu(\mathrm{N})$ & $\mathrm{c}_{\mathrm{v}}(\%)$ & $\mu(\mathrm{mm})$ & $\mathrm{c}_{\mathrm{v}}(\%)$ \\
\hline Lab1 & 1849 & 3.6 & 1336 & 6.6 & 251 & 1.9 & 1898 & 2.6 & 1.63 & 1.2 \\
\hline Lab2 & 2017 & 3.4 & 1626 & 3.1 & 296 & 4.9 & 1940 & 1.3 & 1.72 & 2.1 \\
\hline Lab3 & 1795 & 2.1 & 981 & 10.5 & 241 & 7.4 & 1916 & 1.4 & 1.64 & 1.7 \\
\hline Lab4 & 1715 & 4.1 & 1181 & 6.6 & 335 & 6.8 & 1930 & 1.8 & 1.47 & 2.6 \\
\hline Lab5 & 2006 & 1.9 & 1257 & 3.4 & 394 & 3.8 & 1982 & 2.0 & 1.71 & 1.3 \\
\hline All labs & 1876 & 7.1 & 1276 & 18.5 & 303 & 20.7 & 1940 & 1.6 & 1.63 & 6.1 \\
\hline
\end{tabular}

Table 8: Mean value $\mu$ and coefficient of variation $c_{v}$ of results of SP tests at $300{ }^{\circ} \mathrm{C}$, standard geometry

\begin{tabular}{|c|c|c|c|c|c|c|c|c|c|c|}
\hline & \multicolumn{2}{|c|}{$\mathrm{E}_{\text {to }}$ up to $\mathrm{u}_{\mathrm{m}}$} & \multicolumn{2}{|c|}{$\mathrm{E}_{\mathrm{pl}}$ up to $\mathrm{u}_{\mathrm{m}}$} & \multicolumn{2}{|c|}{$\mathrm{F}_{\mathrm{e}}$} & \multicolumn{2}{|c|}{$\mathrm{F}_{\mathrm{m}}$} & \multicolumn{2}{|c|}{$\mathrm{u}_{\mathrm{m}}$} \\
\hline & $\mu(\mathrm{mJ})$ & $\mathrm{c}_{\mathrm{v}}(\%)$ & $\mu(\mathrm{mJ})$ & $\mathrm{c}_{\mathrm{v}}(\%)$ & $\mu(\mathrm{N})$ & $\mathrm{c}_{\mathrm{v}}(\%)$ & $\mu(\mathrm{N})$ & $\mathrm{c}_{\mathrm{v}}(\%)$ & $\mu(\mathrm{mm})$ & $\mathrm{c}_{\mathrm{v}}(\%)$ \\
\hline Lab1 & 1446 & 4.9 & 1031 & 6.9 & 213 & 7.1 & 1633 & 3.7 & 1.54 & 1.3 \\
\hline Lab2 & 1533 & 3.4 & 1279 & 5.8 & 266 & 6.1 & 1638 & 2.3 & 1.58 & 0.9 \\
\hline Lab3 & 1422 & 2.1 & $654^{1)}$ & $7.5^{1)}$ & 219 & 12.3 & 1608 & 2.9 & 1.62 & 1.8 \\
\hline Lab4 & 1592 & 2.5 & 1131 & 13.4 & 251 & 8.1 & 1692 & 1.8 & 1.65 & 2.3 \\
\hline Lab5 & 1457 & 3.6 & 944 & 9.3 & 321 & 7.3 & 1634 & 2.7 & 1.53 & 0.8 \\
\hline All labs & 1490 & 4.7 & 1012 & 22.4 & 258 & 15.7 & 1641 & 1.9 & 1.58 & 3.2 \\
\hline
\end{tabular}

Figure 9 shows averaged load-displacement curves of tests of Lab1 - Lab3 at $300{ }^{\circ} \mathrm{C}$ using samples of $0.25 \mathrm{~mm}$ thickness. The larger diameter of the lower die hole in the case of Lab2 (cf. Table 5) gives rise to a lower maximum load and a higher displacement $\mathrm{u}_{\mathrm{m}}$ at maximum load. Detailed results of the SP tests with small specimens at $300{ }^{\circ} \mathrm{C}$ are given in Table 9 . However, we can only evaluate the repeatability of results for the individual labs. The calculation of average $c_{v}$-values is not meaningful because we have results of only three labs and because of the difference in the lower die diameter as a main geometrical parameter.

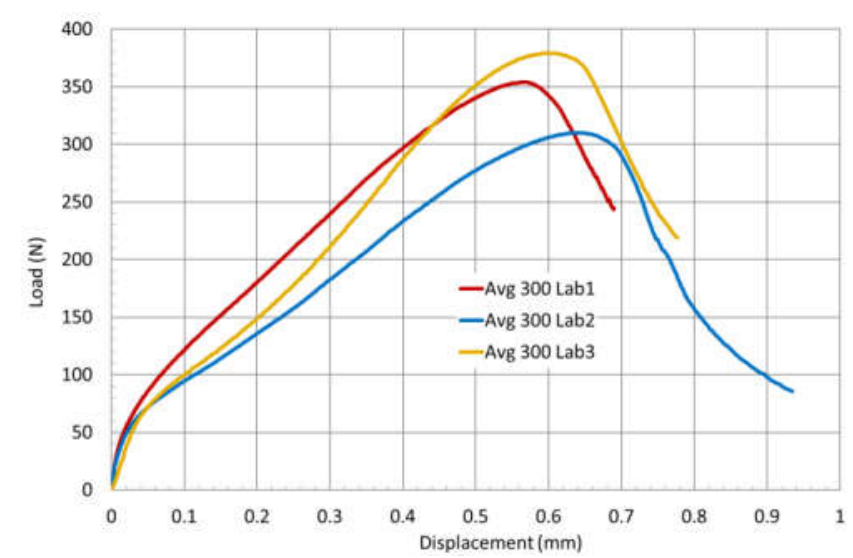

Figure 9: Comparison of load-displacement curves of tests at $300{ }^{\circ} \mathrm{C}$; averaged curves out of 5 tests; T91-DEM specimen thickness $0.25 \mathrm{~mm}$

Table 9: Mean value $\mu$ and coefficient of variation $c_{v}$ of results of SP tests at $300{ }^{\circ} \mathrm{C}$, small geometry

\begin{tabular}{|c|c|c|c|c|c|c|c|c|c|c|}
\hline & \multicolumn{2}{|c|}{$\mathrm{E}_{\mathrm{to}}$ up to $\mathrm{u}_{\mathrm{m}}$} & \multicolumn{2}{|c|}{$\mathrm{E}_{\mathrm{pl}}$ up to $\mathrm{u}_{\mathrm{m}}$} & \multicolumn{2}{|c|}{$\mathrm{F}_{\mathrm{e}}$} & \multicolumn{2}{|c|}{$\mathrm{F}_{\mathrm{m}}$} & \multicolumn{2}{|c|}{$\mathrm{u}_{\mathrm{m}}$} \\
\hline & $\mu(\mathrm{mJ})$ & $\mathrm{c}_{\mathrm{v}}(\%)$ & $\mu(\mathrm{mJ})$ & $\mathrm{c}_{\mathrm{v}}(\%)$ & $\mu(\mathrm{N})$ & $\mathrm{c}_{\mathrm{v}}(\%)$ & $\mu(\mathrm{N})$ & $\mathrm{c}_{\mathrm{v}}(\%)$ & $\mu(\mathrm{mm})$ & $\mathrm{c}_{\mathrm{v}}(\%)$ \\
\hline Lab1 & 157 & 7.3 & 113 & 5.3 & 81 & 6.8 & 411 & 2.3 & 0.568 & 4.2 \\
\hline Lab2 & 122 & 3.5 & 104 & 5.2 & 50 & 9.7 & 310 & 2.4 & 0.639 & 1.9 \\
\hline Lab3 & 133 & 9.7 & 91.3 & 13.0 & 63 & 15.8 & 380 & 7.3 & 0.605 & 1.9 \\
\hline
\end{tabular}

Three different geometrical configurations were used to correlate $F_{e} / h^{2}$ with $R_{p 02}$. As for $R_{m}$ it is not clear from the literature, whether it should be correlated with $F_{m} /\left(u_{m} \cdot h\right)$ or with $F_{m} / h^{2}$. Therefore both correlations are given (Table 10). 
Table 10: Correlations of $R_{p 02}$ with $F_{e}$ and of $R_{m}$ with $F_{m}$

\begin{tabular}{llllll}
\hline & $\begin{array}{l}\text { Lab1 data } \\
\text { Standard geometry }\end{array}$ & $\begin{array}{l}\text { Lab2 data } \\
\text { Standard geometry }\end{array}$ & $\begin{array}{l}\text { Lab4 data } \\
\text { Standard geometry }\end{array}$ & $\begin{array}{l}\text { Lab2 data } \\
\text { Small geometry 2 }\end{array}$ & $\begin{array}{l}\text { Lab1 data } \\
\text { Small geometry 1 }\end{array}$ \\
\hline$\beta_{\text {YS }}$ (Eq. 3) & 0.60 & 0.49 & 0.48 & 0.63 & 0.42 \\
\hline$\beta_{\text {UTS }}$ (Eq. 4a) & 0.09 & 0.09 & -- & 0.11 & 0.10 \\
\hline$\beta_{\text {UTS }}$ (Eq. 4b) & 0.25 & 0.26 & 0.21 & 0.26 & 0.19 \\
\hline
\end{tabular}

The ductile to brittle transition temperatures were estimated by using the total energy up to $\mathrm{u}_{\mathrm{m}}$ since the uncertainty for the plastic energy is significantly higher (Table 7 to Table 9). The results of the two curve fitting procedure for the temperature dependence of the total energies $\mathrm{E}_{\mathrm{SP}}(\mathrm{T})$ and the corresponding ductile to brittle transition temperatures are given in Table 11 for the standard geometry and in Table 12 for the small geometry. Note however, that even for the tests in liquid nitrogen (at $-196{ }^{\circ} \mathrm{C}$ ) the lower shelf was not reached (cf. Fig. 6).

Table 11: Parameters of the $E_{\text {to }}(T)$ fit, transition temperatures and $\alpha$ coefficients, T91-DEM, standard discs (0.5 mm); based on total energies up to $u_{m}$

\begin{tabular}{lllll}
\hline Parameter & Lab1 & Lab2 & Lab3 & Lab4 \\
& $\varnothing 8 \times 0.5$ & $10 \times 10 \times 0.5$ & $\varnothing 8 \times 0.5$ & $\varnothing 8 \times 0.5$ \\
\hline $\mathrm{A}_{\mathrm{b}}(\mathrm{J})$ & 0.00232 & 0 & 0 & 0 \\
$\mathrm{~B}_{\mathrm{b}}(\mathrm{J})$ & 0.217 & 0.314 & 0.209 & 0.1545 \\
$\mathrm{C}_{\mathrm{b}}(1 / \mathrm{K})$ & 0.0173 & 0.0162 & 0.0225 & 0.0191 \\
$\mathrm{~A}_{\mathrm{d}}(\mathrm{J})$ & 1.292 & 1.382 & 1.560 & 0 \\
$\mathrm{~B}_{\mathrm{d}}(\mathrm{J})$ & 2.347 & 3.290 & 4.311 & 1.7685 \\
$\mathrm{C}_{\mathrm{d}}(1 / \mathrm{K})$ & -0.00478 & -0.00542 & -0.00585 & -0.0074 \\
\hline $\mathrm{T}_{\mathrm{SP}}\left({ }^{\circ} \mathrm{C}\right)$ & -167 & -172 & -178 & -167 \\
\hline$\alpha$ & 0.44 & 0.42 & 0.40 & 0.44 \\
\hline
\end{tabular}

Table 12: Parameters of the $E_{t o}(T)$ fit, transition temperatures and $\alpha$ coefficients, T91-DEM, small discs (0.25 mm) based on total energies up to $u_{m}$

\begin{tabular}{llll}
\hline Parameter & Lab1 & Lab2 & Lab3 \\
& $\varnothing 3 \times 0.25$ & $3.5 \times 3.50 .25$ & $\varnothing 3 \times 0.25$ \\
\hline $\mathrm{A}_{\mathrm{b}}(\mathrm{J})$ & 0.0115 & 0 & 0 \\
$\mathrm{~B}_{\mathrm{b}}(\mathrm{J})$ & 0.0164 & 0.09630 & 0.01314 \\
$\mathrm{C}_{\mathrm{b}}(1 / \mathrm{K})$ & 0.0208 & 0.005925 & 0.02032 \\
$\mathrm{~A}_{\mathrm{d}}(\mathrm{J})$ & 0.0912 & 0.09893 & 0.06065 \\
$\mathrm{~B}_{\mathrm{d}}(\mathrm{J})$ & 0.1825 & 0.1900 & 0.1960 \\
$\mathrm{C}_{\mathrm{d}}(1 / \mathrm{K})$ & -0.00328 & -0.003767 & -0.00173 \\
\hline $\mathrm{T}_{\mathrm{SP}}\left({ }^{\circ} \mathrm{C}\right)$ & -183 & -193 & -170 \\
\hline$\alpha$ & 0.38 & 0.33 & 0.43 \\
\hline
\end{tabular}

\subsection{Evaluation of the irradiation effect}

Figure 10 shows averaged load-displacement curves for the $\mathrm{SP}$ tests at $\mathrm{T}=200{ }^{\circ} \mathrm{C}$. The averaged curve for the unirradiated material was calculated from the tests 34 - 36 (cf. Table 6). For averaging at $3.99 \mathrm{dpa}$, the tests HE07 - HE09 were used and for 2.31 dpa the single measurement MA06 is shown. The radiation effect leads to a reduction of the displacement at maximum load $\mathrm{u}_{\mathrm{m}}$ while the maximum load itself $\left(\mathrm{F}_{\mathrm{m}}\right)$ is not significantly affected. 


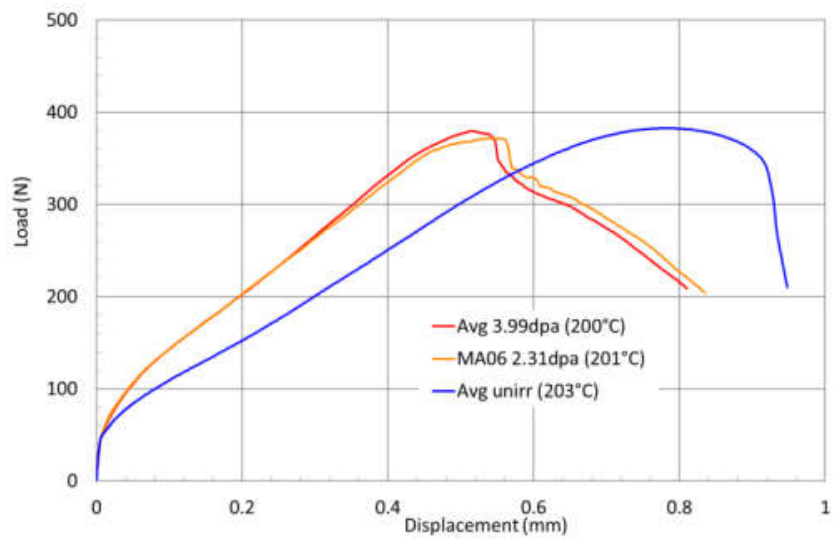

Figure 10: Load-displacement curves at $\mathrm{T}=20{ }^{\circ} \mathrm{C}$ for unirradiated and neutron irradiated T91-SPI, specimen size $4 \times 3 \times 0.3 \mathrm{~mm}$. Averaged curves for unirradiated condition and 3.99 dpa, single measurement MA06 for 2.31 dpa.

The effect of the SP test temperature on $\mathrm{F}_{\mathrm{e}}, \mathrm{F}_{\mathrm{m}}$ and $\mathrm{u}_{\mathrm{m}}$ was analysed for the different irradiation conditions as shown in Figure 11. As already stated above, there is no significant effect of the irradiation on the maximum load $\mathrm{F}_{\mathrm{m}}$. This is true for the whole range of the test temperature. As for the transition load $\mathrm{F}_{\mathrm{e}}$ and the displacement at maximum load $\mathrm{u}_{\mathrm{m}}$, the significance of the irradiation effect depends on the test temperature. A significant increase of $\mathrm{F}_{\mathrm{e}}$ is observed for $\mathrm{T}>-100{ }^{\circ} \mathrm{C}$, whereas a significant decrease of $\mathrm{u}_{\mathrm{m}}$ can be noticed for $\mathrm{T}>0{ }^{\circ} \mathrm{C}$. For lower temperatures, an irradiation effect is either not present or it is covered by the larger scatter of the data.
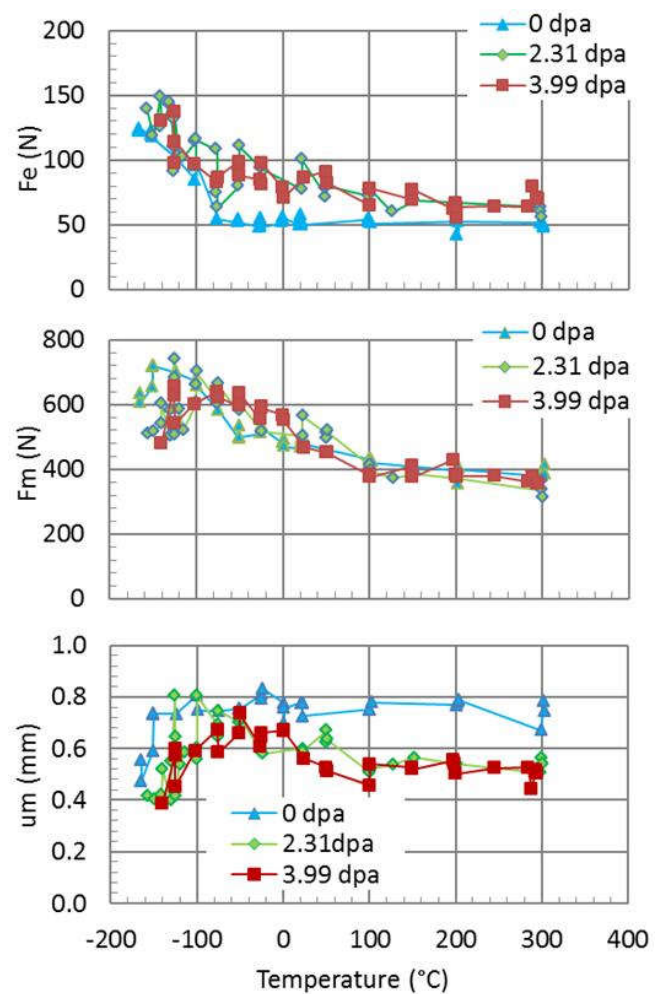

Figure 11: Effect of test temperature and irradiation on: the elastic-plastic transition load $\mathrm{F}_{\mathrm{e}}$ (top), the maximum load $\mathrm{F}_{\mathrm{m}}$ (centre) and displacement at maximum load $\mathrm{u}_{\mathrm{m}}$ (bottom)

The yield stress is estimated from the elastic-plastic transition load $\mathrm{F}_{\mathrm{e}}$ and the initial specimen thickness $h$ using the empirical correlation Eq. (3). The ultimate tensile strength can be estimated from the load-displacement curves either by Eq. (4a) or by Eq. (4b). From Figure 10 it can be concluded that Eq. (4a) would indicate that irradiation has no effect on $R_{m}$ (since 
$\mathrm{F}_{\mathrm{m}}$ is not significantly affected by the neutron dose). This is obviously not the case (cf. Table 3). This speaks for Eq. (4b) being more appropriate.

The pre-factors $\beta_{\text {YS }}$ and $\beta_{\text {UTS }}$ were determined within the collective exercise. For the small geometry (punch diameter $1.0 \mathrm{~mm}$, lower die diameter $1.75 \mathrm{~mm}$ ) values of $\beta_{\mathrm{YS}}=0.63$ and $\beta_{\text {UTS }}=0.26$ were obtained. However, it was also shown that these pre-factors significantly depend on the testing device. As we used a different device for the collective exercise (outside the hot cell lab), a recalculation of these coefficients was necessary. For this we used the SP tests for the unirradiated condition and the tensile data for the unirradiated condition from [17], cf. Figure 2.

Since there is no significant irradiation effect on $\mathrm{F}_{\mathrm{e}}$ and $\mathrm{u}_{\mathrm{m}}$ at low test temperatures (Figure 11) it was decided to use only test data with $\mathrm{T}>0{ }^{\circ} \mathrm{C}$ for the re-calculation of the coefficients $\beta_{Y S}$ and $\beta_{\text {UTS. }}$. The correlations between the YS data from tensile tests (Figure 2) and $F_{e} / h^{2}$ from SP tests and between UTS and $\mathrm{F}_{\mathrm{m}} /\left(\mathrm{h}^{*} \mathrm{u}_{\mathrm{m}}\right)$ respectively were used (cf. section 4.1). The re-calculated coefficients are $\boldsymbol{\beta}_{\mathrm{YS}}=\mathbf{0 . 8 8 4}$ and $\boldsymbol{\beta}_{\mathrm{UTS}}=\mathbf{0 . 3 2 7}$.

These values were used to calculate the tensile properties from the SP tests results by Eq. (3) and Eq. (4b) respectively for all irradiation conditions. As an example, Figure 12 shows the temperature dependent values of the yield stress for $2.31 \mathrm{dpa}$.

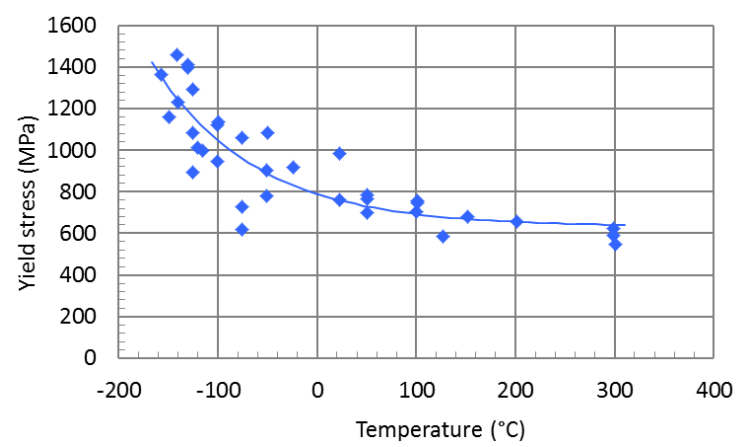

Figure 12: Yield stress vs. temperature obtained from SP tests with fitting curve, T91-SPI, $2.31 \mathrm{dpa}$

Because of the significant scatter of the data we used an exponential fit to describe the $\mathrm{R}_{\mathrm{p} 02}(\mathrm{~T})$ and $R_{m}(T)$ dependences. The resulting fit equations of the tensile properties obtained from the SP tests are given below.

For the unirradiated condition:

$$
\begin{aligned}
& \mathrm{R}_{\mathrm{p} 02}(\mathrm{MPa})=466+4627 \cdot \exp [-0.0159 \cdot \mathrm{T}(\mathrm{K})] \\
& \mathrm{R}_{\mathrm{m}}(\mathrm{MPa})=564+2204 \cdot \exp [-0.0106 \cdot \mathrm{T}(\mathrm{K})]
\end{aligned}
$$

For the neutron dose $2.31 \mathrm{dpa}$ :

$$
\begin{aligned}
& \mathrm{R}_{\mathrm{p} 02}(\mathrm{MPa})=632+2203 \cdot \exp [-0.010 \cdot \mathrm{T}(\mathrm{K})] \\
& \mathrm{R}_{\mathrm{m}}(\mathrm{MPa})=724+1623 \cdot \exp [-0.0084 \cdot \mathrm{T}(\mathrm{K})]
\end{aligned}
$$

For the neutron dose 3.99 dpa:

$$
\begin{aligned}
& R_{\mathrm{p} 02}(\mathrm{MPa})=664+2172 \cdot \exp [-0.0104 \cdot \mathrm{T}(\mathrm{K})] \\
& \mathrm{R}_{\mathrm{m}}(\mathrm{MPa})=793+1764 \cdot \exp [-0.0093 \cdot \mathrm{T}(\mathrm{K})]
\end{aligned}
$$


The ductile to brittle transition temperature was evaluated from the $\mathrm{E}_{\mathrm{SP}}(\mathrm{T})$ data. The total energy up to the maximum load was used. A two-curve fitting procedure was applied as described in section 3.1. For the neutron dose $2.31 \mathrm{dpa}$ (specimens KR, KS and MA), a SP transition temperature $\mathrm{T}_{\mathrm{SP}}$ of $-148^{\circ} \mathrm{C}$ was obtained. For the dose of $3.99 \mathrm{dpa}$ (specimens $\mathrm{HE}$ and $\mathrm{HH}$ ), a SP transition temperature of $-139{ }^{\circ} \mathrm{C}$ was derived (Figure 13).

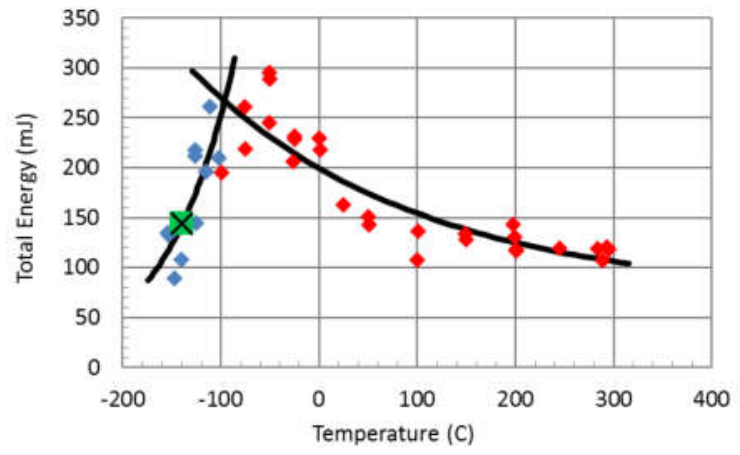

Figure 13: Determination of the DBTT for T91-SPI (3.99 dpa) using the total energy up to $u_{m}\left(T_{S P}=-139{ }^{\circ} \mathrm{C}\right)$

The transition temperature of the unirradiated condition was evaluated to $\mathrm{T}_{\mathrm{SP}}=-174{ }^{\circ} \mathrm{C}$ from tests 01-39. However, the accuracy of this result is considered insufficient because the temperature range of the tests does not provide lower shelf data. The transition temperature is significantly lower than the minimum test temperature. More tests at liquid nitrogen temperature would be needed, but this was not possible in the hot cell.

\section{Discussion}

\subsection{Collective exercise}

The scatter of results (expressed by coefficient of variation $\mathrm{c}_{\mathrm{v}}$ ) for the total and plastic energy $\left(\mathrm{E}_{\mathrm{to}}\right.$ and $\left.\mathrm{E}_{\mathrm{pl}}\right)$, the elastic-plastic transition load $\left(\mathrm{F}_{\mathrm{e}}\right)$, the maximum load $\left(\mathrm{F}_{\mathrm{m}}\right)$ and the displacement at maximum load $\left(\mathrm{u}_{\mathrm{m}}\right)$ was analysed for tests at room temperature and at $300{ }^{\circ} \mathrm{C}$ using the standard geometry (cf. Table 7 and Table 8 ). The best repeatability $\left(\mathrm{c}_{\mathrm{v}}\right.$-values for the individual labs) is obtained for the maximum load $\mathrm{F}_{\mathrm{m}}\left(\mathrm{c}_{\mathrm{v}}=1.3 \% \ldots 3.7 \%\right)$ and for the displacement at maximum load $\mathrm{u}_{\mathrm{m}}\left(\mathrm{c}_{\mathrm{v}}=0.9 \% \ldots 2.6 \%\right)$. For these two parameters we also obtained the lowest average $\mathrm{c}_{\mathrm{v}}$-values indicating a minor device dependence. In contrast, we observe quite high values of the lab specific $\mathrm{c}_{\mathrm{v}}$ for $\mathrm{F}_{\mathrm{e}}(1.9 \% \ldots 12.3 \%)$ and $\mathrm{E}_{\mathrm{pl}}$ $(3.1 \% \ldots 13.4 \%)$ and the corresponding $\mathrm{c}_{\mathrm{v}}$ for all labs (up to $22.4 \%$ ) which indicates a less good repeatability and a higher device dependence. In the case of $\mathrm{E}_{\mathrm{pl}}$ this is a consequence of its dependence on the bilinear fit for $\mathrm{F}_{\mathrm{e}}$ (cf. Eq. 8). In general, the average $\mathrm{c}_{\mathrm{v}}$-value are significantly higher than the corresponding lab specific values. Thus, the differences due to the device dependence are more significant than the scatter on one and the same device. Possible reasons for the differences in the load-displacement curves from different devices can be, besides the difference in the diameter and edge radius of lower die hole: i) accuracy of the displacement measurement, ii) deviations of the puncher from the ideal semi-spherical shape, iii) elastic deformation of the puncher, iv) missing or insufficient correction of the displacements for the machine compliance. The comparison of the results of the different geometries shows that the scatter is slightly higher for the small geometry (Table 8 and Table 9).

The rather significant device dependence of $\mathrm{F}_{\mathrm{e}}$ also gives rise to the fact that there is no unitary yield stress coefficient $\beta_{Y S}$ (Table 10). This coefficient depends on the main geometry 
of the SP set-up. However, even in case of identical main geometrical parameters the coefficient seems to be device dependent as shown by the results of Lab1, Lab2 and Lab4 for the standard geometry (Table 10). The coefficient $\beta_{\text {UTS }}$ was not found to be device dependent if the correlation Eq. (4a) is used; all values are between 0.09 and 0.11 . However, it is supposed that Eq. (4a) is not an appropriate correlation for the UTS (cf. sections 4.2 and 5.2). If correlation Eq. (4b) is used the coefficient $\beta_{\mathrm{UTS}}$ is device dependent. Nevertheless, Eq. (4b) is more appropriate than Eq. (4a).

In addition to these findings of the collective exercise it can be supposed that $\beta_{Y S}$ depends also on the hardening behaviour of the material, because the deformation state in the SP specimen is highly non-uniform [13]. The plastic deformation starts in the centre of the disc and proceeds to the peripheral regions. The plastic strain at the load $\mathrm{F}_{\mathrm{e}}$ and displacement $\mathrm{u}_{\mathrm{A}}$ (cf. Figure 4) ranges from 0 to ca. 10\%.This is demonstrated by a finite element simulation of the SP test for the standard geometry at room temperature. Figure 14 shows the load and the plastic strain at two locations as a function of the puncher displacement. The elastic-plastic transition load $\mathrm{F}_{\mathrm{e}}$ evaluated according to Figure 4 is also included.

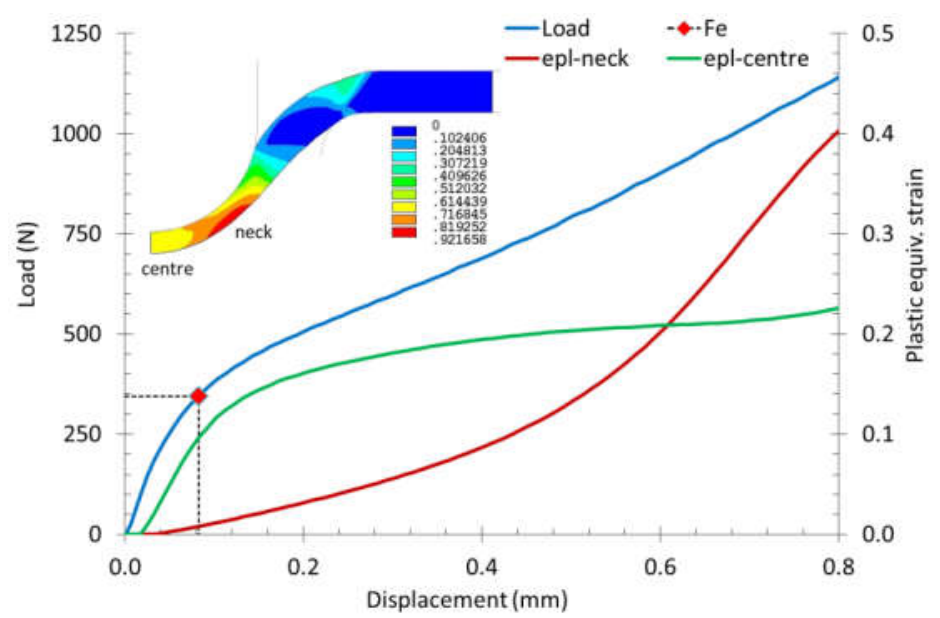

Figure 14: Finite element simulation of the SP test (standard geometry at RT); load and plastic strain as function of puncher displacement; T91-DEM; the insert shows the plastic strain distribution at $\mathbf{u}_{\mathrm{m}}=1.8 \mathrm{~mm}$.

It can be concluded that the maximum plastic strain in the SP sample at load level $\mathrm{F}=\mathrm{F}_{\mathrm{e}}$ is much higher than the value of $0.2 \%$ which corresponds to $R_{p 02}$. Thus, $F_{e}$ (and thereby $\beta_{Y S}$ ) is affected by the work hardening of the material.

For the estimation of the ductile to brittle transition temperature $\mathrm{T}_{\mathrm{SP}}$, the total energy is better suited than the plastic energy. The plastic energies exhibit a significantly larger scatter due to the dependence on $\mathrm{F}_{\mathrm{e}}$ (Eq. 8). For the tests of Lab1 and Lab2, the $\alpha$ values obtained with $0.25 \mathrm{~mm}$ samples are smaller than those obtained with the $0.5 \mathrm{~mm}$ samples. Surprisingly, a slightly higher $\alpha$ value is obtained with the $0.25 \mathrm{~mm}$ samples for the tests of Lab3. It is also interesting to note that the estimated $\mathrm{T}_{\mathrm{SP}}$ values of Lab1 and Lab4 based on $0.5 \mathrm{~mm}$ samples are very close, even though the load-displacement curves are different (Figure 8) and even though the fit parameters are different (Table 11). This speaks for the robustness of the chosen fit procedure. In general, the transition temperature $\mathrm{T}_{\mathrm{SP}}$ decreases with smaller specimen thickness. This implies a need for very low test temperatures for $0.25 \mathrm{~mm}$ specimens in order to have a sufficient number of specimens that fail at low energy. For ductile materials $\left(\mathrm{T}_{\mathrm{CVN}}<-40{ }^{\circ} \mathrm{C}\right)$ it is not always possible to get lower shelf data since usually the lowest possible test temperature is around $-196^{\circ} \mathrm{C}$ (liquid nitrogen). This leads to an uncertainty of the DBTT and might also reduce the inter-laboratory reproducibility. 


\subsection{Irradiation induced hardening and embrittlement}

In Figure 15, the temperature dependent yield strength obtained from the SP tests (section 4.2) is compared with results from tensile tests in the SPIRE project [17]. As there are only two tensile tests available for the irradiated condition from the T91-SPI heat, we included also literature data into the comparison [21]. The curves for the SP data are based on the fit equations given in section 4.2 (Eqs. 10-12).

For the unirradiated condition (blue curves) there is a good agreement of all data for temperatures $\mathrm{T}>0{ }^{\circ} \mathrm{C}$. For low temperatures, the agreement is less good even for the data from tensile tests. The SP based data result in an overestimation of the yield strength in comparison to the values from the tensile tests.

A clear irradiation effect on the yield stress is observed. However, the two tensile tests from the SPIRE project (cf. Table 3) suggest a significantly higher hardening effect than it is obtained from the SP data. Interestingly, the tensile data from [21] show a better agreement with our SP data. Nevertheless it has to be mentioned that the data in [21] are based on a different T91 heat (but with a similar heat treatment) irradiated at $300{ }^{\circ} \mathrm{C}$.

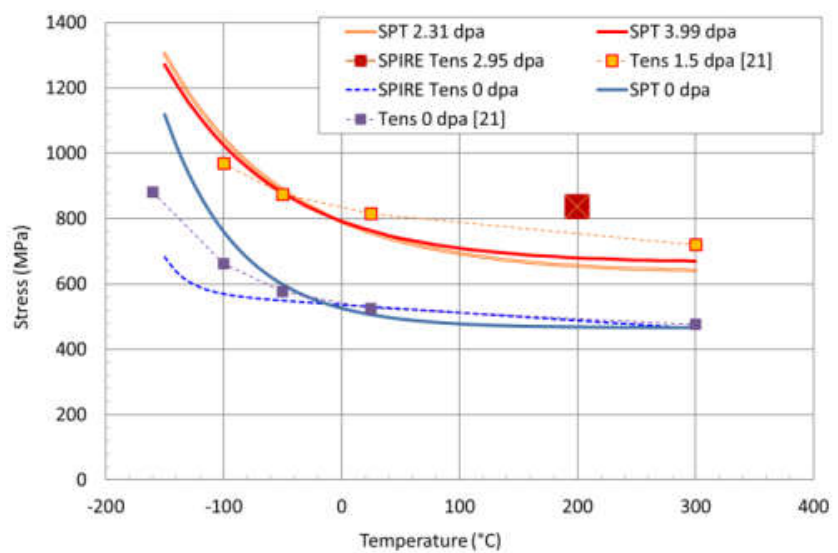

Figure 15: Yield stress vs. temperature of T91 obtained from SP and tensile tests for different neutron doses

Figure 16 shows the corresponding results for the ultimate tensile strength. For the unirradiated condition, the SP based data overestimate the UTS measured in the tensile tests in the range of low temperatures $\left(\mathrm{T}<0{ }^{\circ} \mathrm{C}\right)$ as already observed for the yield strength. The evaluation of the irradiation induced increase of the UTS at $200{ }^{\circ} \mathrm{C}$ agrees well with the tensile test result. 


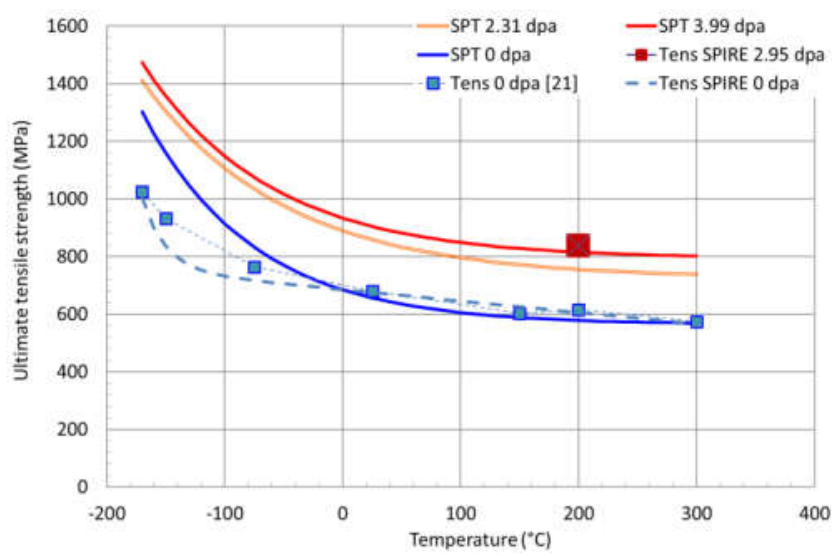

Figure 16: Ultimate tensile strength vs. temperature of T91 obtained from SP and tensile tests for different neutron doses

The distance between the SP based curves of the irradiated condition and the unirradiated reference is decreasing with decreasing temperature (Figure 15 and Figure 16), i.e. a significantly lesser irradiation induced hardening $\left(\Delta \mathrm{R}_{\mathrm{p} 02}\right.$ and $\left.\Delta \mathrm{R}_{\mathrm{m}}\right)$ is indicated at low test temperatures. This is due to the fact that the irradiation effect is not observed in the transition load $\left(\mathrm{F}_{\mathrm{e}}\right)$ and the displacement at maximum load $\left(\mathrm{u}_{\mathrm{m}}\right)$ for low temperatures (Figure 11). Since tensile data for low temperatures are missing for the irradiated condition of T91-SPI, it cannot be decided whether or not there is an irradiation hardening effect at low temperatures.

Anyway, Song et al. demonstrated that irradiation hardening may be overwhelmed by the yield stress increase at low temperatures [22].

The SP transition temperatures can be translated into Charpy transition temperatures by Eq. (1). The conversion factor was determined as $\alpha=0.336$. The translation between the KLST transition temperature and the Charpy transition temperature is given by Eq. (7). In Table 13, the transition temperatures available for the T91-SPI heat are summarized. The comparison of $\mathrm{T}_{\mathrm{SP}}$ and $\mathrm{T}_{\mathrm{KLST}}$ is done via the recalculation of $\mathrm{T}_{\mathrm{CVN}}$ according to the relations above. For the unirradiated condition, the KLST based transition temperature was taken as reference since the SP based value is not reliable (cf. section 4.2).

Table 13: Ductile to brittle transition temperatures obtained from SP tests and KLST tests [17] and recalculated Charpy transitions
temperatures
\begin{tabular}{lllll}
\hline & measured in MATTER & measured in SPIRE [17] & Recalculated \\
\hline $\mathrm{dpa}$ & $\mathrm{T}_{\mathrm{SP}, 0.3}\left({ }^{\circ} \mathrm{C}\right)$ & $\mathrm{T}_{\mathrm{KLST}}\left({ }^{\circ} \mathrm{C}\right)$ & $\mathrm{T}_{\mathrm{CVN}}\left({ }^{\circ} \mathrm{C}\right)$ & -8 \\
\hline 0 & $(-186){ }^{1)}$ & -73 & 99 & -- \\
\hline 2.31 & -148 & -- & 100 & 107 \\
\hline 2.43 & -- & 35 & 122 & 108 \\
\hline 3.58 & -- & 57 & 126 & 130 \\
\hline 3.99 & -139 & -- & $\mathrm{T})$ \\
\hline
\end{tabular}

1) Recalculated from $T_{\text {KLST }}$

The recalculated Charpy transition temperature shifts in dependence of the neutron dose are shown in Figure 17. The agreement between the SP based values and the KLST based values [17] is very good. Hence the SP test is an appropriate tool for the screening of radiation embrittlement. It should be noted that the SP specimens used to obtain $\mathrm{T}_{\mathrm{SP}}$ for one irradiation condition were manufactured from 2 KLST specimens only, whereas the determination of $\mathrm{T}_{\mathrm{KLST}}$ for one irradiation condition was based on 12 KLST specimens [17]. 


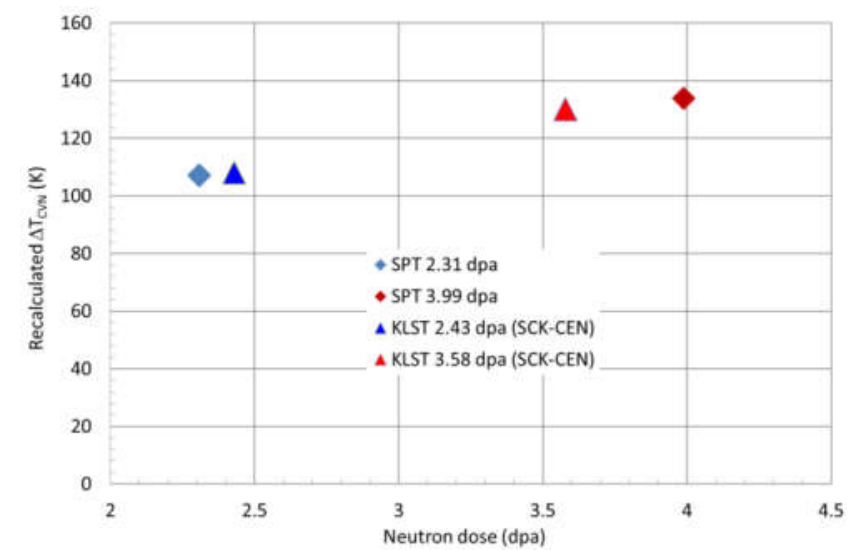

Figure 17: Charpy transition temperature shift $\Delta \mathrm{T}_{\mathrm{CVN}}(\mathrm{K})$, recalculated from SP tests $(4 \times 3 \times 0.3)$ and from KLST tests, vs. neutron dose, T91-SPI

\section{Conclusions}

A small punch test collective exercise was conducted in order to evaluate systematically the scatter and reproducibility of results. Eight groups of data sets for two basic set-up geometries were generated by five participating laboratories.

The relative scatter of results (expressed by coefficient of variation) for the total and plastic energy $\left(\mathrm{E}_{\mathrm{to}}\right.$ and $\left.\mathrm{E}_{\mathrm{pl}}\right)$, the elastic-plastic transition load $\left(\mathrm{F}_{\mathrm{e}}\right)$, the maximum load $\left(\mathrm{F}_{\mathrm{m}}\right)$ and the displacement at maximum load $\left(\mathrm{u}_{\mathrm{m}}\right)$ was analysed for tests at room temperature and at $300{ }^{\circ} \mathrm{C}$. The largest scatter was observed for $\mathrm{F}_{\mathrm{e}}$ and $\mathrm{E}_{\mathrm{pl}}$. The lab-to-lab differences are more significant than the scatter of data from one and the same lab. The comparison of the results of the different geometries shows that the scatter is slightly higher for the small geometry. Correlations for the estimation of tensile properties were shown to be device dependent. The estimations of the transition temperatures $\mathrm{T}_{\mathrm{SP}}$ are in a good agreement in cases of identical main geometrical parameters. The total small punch energy up to the maximum load seems to be a good choice for the $\mathrm{E}_{\mathrm{SP}}(\mathrm{T})$ fit.

The irradiation effect is manifested in the load-displacement curves of the small punch test by an increased elastic-plastic transition load $\left(\mathrm{F}_{\mathrm{e}}\right)$ and by a reduced displacement at maximum load $\left(\mathrm{u}_{\mathrm{m}}\right)$. The maximum load $\left(\mathrm{F}_{\mathrm{m}}\right)$ is not significantly affected. For lower test temperatures the irradiation effect on $\mathrm{F}_{\mathrm{e}}$ and $\mathrm{u}_{\mathrm{m}}$ cannot be observed in the SP tests. Since tensile data at lower temperatures for the irradiated material are missing, it could not be decided whether the irradiation effect is not present at lower test temperatures or whether it is obscured by the larger scatter of the SP data.

The recalculated Charpy transition temperature shifts obtained from SP tests are in remarkable agreement with KLST based values. The SP test is an appropriate tool for the screening of the neutron irradiation induced embrittlement in terms of transition temperature shift. Nevertheless it is hardly possible to obtain lower shelf energy data for the unirradiated condition, in particular when small SP discs (thickness $0.25 \mathrm{~mm}$ or $0.3 \mathrm{~mm}$ ) are used instead of standard discs (thickness $0.5 \mathrm{~mm}$ ). Therefore transition temperatures from KLST or even Charpy tests have to be taken into account additionally for the unirradiated condition. In many cases, this does not pose a strong restriction, because the SP test is the method of choice in case of limited availability and/or high activity just of the irradiated material.

Tensile properties can also be determined from SP test. We observed a significant effect of irradiation on hardening $\left(\mathrm{R}_{\mathrm{p} 02}\right)$. In comparison with tensile data, the irradiation induced 
hardening was underestimated. It was found to be inevitable, that the SP tests for the unirradiated and for the irradiated conditions have to be performed with one and the same SP device since the conversion factor between the elastic-plastic transition load and the yield strength is strongly device dependent. The correlations for tensile properties (coefficients $\beta_{Y S}$ and $\left.\beta_{\text {UTS }}\right)$ cannot be used for low temperatures $\left(\mathrm{T}<0{ }^{\circ} \mathrm{C}\right)$. All in all the SP test is more appropriate for the screening of embrittlement than it is for hardening.

\section{Acknowledgements}

This work was partly supported by the European community within the FP7 project MATTER under Grant Agreement No. 269706. The authors would also like to express their gratitude to Dr Serguei Gavrilov (SCK•CEN Mol) for the supply of unirradiated and neutron irradiated T91 steels.

\section{References}

[1] G.E. Lucas, Metallurgical Transactions A 21A (1990) 1105-1119

[2] T. Misawa, T. Adachi, M. Saito, Y. Hamaguchi, J. Nucl. Mater. 150 (1987) 194-202.

[3] X. Jia, Y. Dai Y., J. Nucl. Mater. 323 (2003) 360-367.

[4] J.S. Ha, E. Fleury, KSME Int. Journal 12 (1998) 5 818-826

[5] CEN Workshop Agreement CWA 15627: Small Punch Test Method for Metallic Materials. European Committee for Standardization Document CWA 15627:2006 E, 2006

[6] J. McNaney, G.E. Lucas, G.R. Odette, J. Nucl. Mater. 179-181 (1991) 429-433.

[7] M.C. Kim, Y.J. Oh, B.S. Lee: The evaluation of ductile-brittle transition temperature before and after neutron irradiation in RPV steels using a small punch test. Transactions 17th Int. Conf. on Structural Mechanics in Reactor Technology (SMiRT 17), 2003, paper G01-6

[8] J. Kameda, Acta Metallurgica, 34(12), 2391-2398

[9] J. Kameda, X. Mao, J. Material Science 27 (1992) 983-989.

[10] E.N. Campitelli, P. Spaetig, R. Bonade, W. Hoffelner, M. Victoria, J. Nucl. Mater. 335 (2004) 366-378.

[11] K. Matocha, M. Filip, S. Stejskalova, Determination of Critical Temperature of Brittleness $\mathrm{T}_{\mathrm{k} 0}$ by Small Punch Tests, COMAT 2012, , Plzen Czech Republic, 21-22 ${ }^{\text {nd }}$ Nov, 2012

[12] X. Mao, H. Takashi, J. Nucl. Mater. 150 (1987) 42-52.

[13] T.S. Byun, E.H. Lee, J.D. Hunn, K. Farrell, L.K. Mansur, J. Nucl. Mater. 294 (2001) 256-266

[14] M. Abendroth, M. Kuna, Engng. Fract. Mech. 73 (2006) 710-725.

[15] T. Linse, M. Kuna, J. Schuhknecht, H.W. Viehrig, Engng. Fract. Mech. 75 (2008) 3520-3533.

[16] J. van den Bosch, A. Almazouzi, EUROTRANS-DEMETRA Deliverable D4.2: Procurement and Characterisation of T91 and SS316L plates, SCK-CEN report R-4197, July 2005

[17] E. Lucon, A. Almazouzi, Mechanical Response to Irradiation at $200^{\circ} \mathrm{C}$ for EM10, T91 and HT9 - Final Report: Specimens Irradiated to 2.6 and 3.9 dpa, SCK-CEN, Mol, Final Report, SPIRE Project SCK-CEN-BLG-986, 2004.

[18] E. N. Klausnitzer, Materialprüfung, 33 (1991) 5, 132-134

[19] K. Turba, R. Hurst, P. Haehner, Int. J. Pressure Vessels and Piping 111-112(2013) 155161

[20] Y.W. Ma, K.B. Yoon, Materials Science and Engineering A 527 (2010) 3630-3638

[21] M. Matijasevic, E. Lucon, A. Almazouzi, J. Nucl. Mater. 377 (2008) 101-108 
[22] S.-H. Song, R.G. Faulkner, P.E.J. Flewitt, P. Marmy, L.-Q. Wenig, Materials Characterisation 53(2004)1, 35-41 


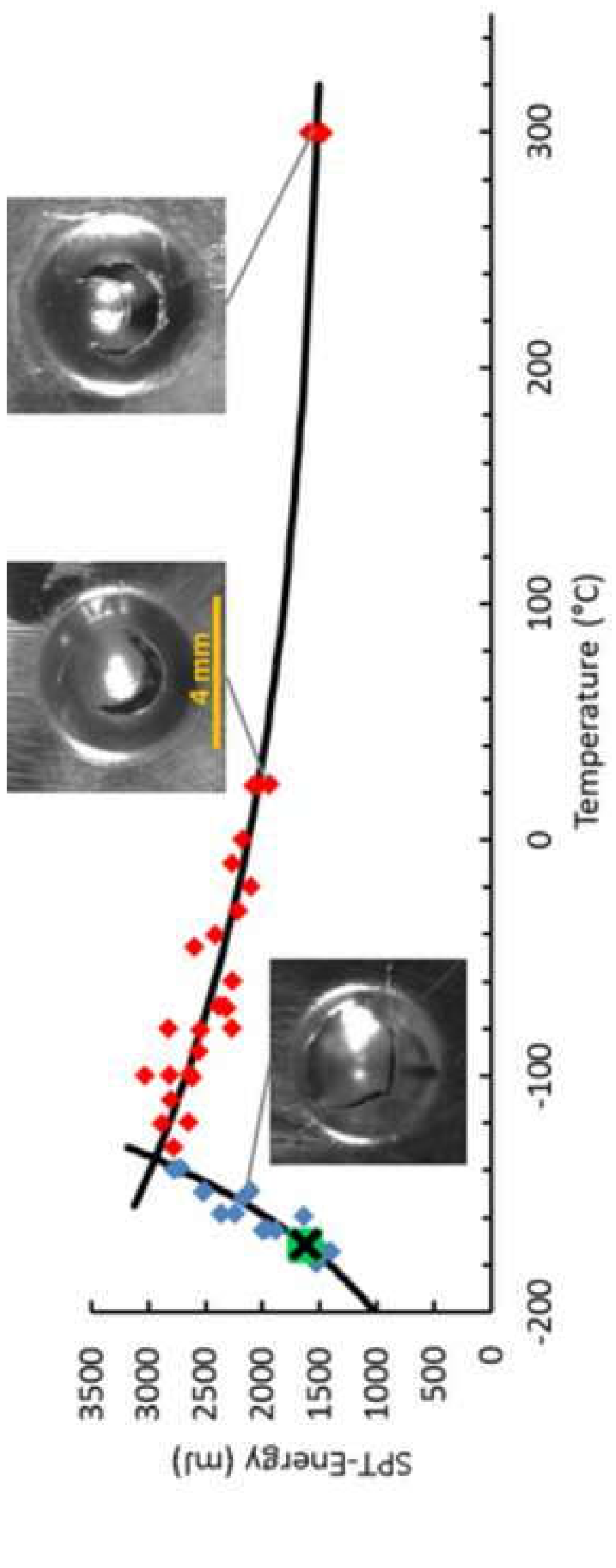




\section{Highlights (for review)}

- Collective exercise on the small punch test

- Statistical evaluation of in-house repeatability and inter-laboratory reproducibility

- Evaluation of neutron irradiation induced hardening and embrittlement of T91 steel by small punch test

- Small punch test well suited for screening of embrittlement and conditionally suited for hardening 


\section{Response to the comments of the reviewers}

Reviewer 1: "The paper is clearly written, figures and tables are appropriate and references are correctly given.Result are clearly presented and discussed in terms of their scatter and reproducibility between different machines/laboratory as well as their accuracy with respect to quantities obtained using standard test procedures. I recommend publication. “

No response or action is needed.

Reviewer 2: "The manuscript describes the results of a collective exercise carried out in the frame of work package 2 of the Euratom FP7-MATTER project to evaluate the potential of small punch test for the characterization of irradiation hardening and embrittlement. No original matter is presented therefore the manuscript does not deserve to be published in Journal of Nuclear Materials. "

Response: Indeed, the small punch test has been applied for many years to extract tensile properties and transition temperatures. Nevertheless, the paper presents new aspects on this testing method.

(I): Within the collective exercise, a systematic and statistically based analysis of the reproducibility and device dependence of small punch test results was performed. This allows an evaluation of the accuracy and trustworthiness of material properties extracted from the small punch test. The authors are not aware of comparable studies reported in the literature.

(II): The paper also includes the evaluation of neutron irradiation induced hardening and embrittlement of T91for two dose levels by the small punch test and provides a direct comparison with results from tensile test and impact tests. A FEM-based substantiation is given for the fact that radiation embrittlement can more reliably detected by small punch testing than radiation hardening (cf. Fig 14). This has not been demonstrated in earlier papers.

Of course, all presented small punch test results are original data, which were not published elsewhere. We have tried to make the originality of our results more clear in the revised paper (especially abstract, introduction and conclusions).

Reviewer 3: "An excellent paper and a very valuable contribution to the SP community and standardisation. Chapter 1: Charpy specimen size is 10*10*55 (not 50), thus the volume ratio becomes 220. In Figs 6 and 13 the green points are poorly visible and would not be visible at all in a $B \& W$ copy. Use an other marker instead: $a$ black circle for example. Chapter 5.2 write "blue curves" instead of "blue tone curves". On top of Table 13 write "reliable" instead of "trustable" “

Response: The volume ratio Charpy/SPT was corrected in Chapter 1. Figures 6 and 13 were modified accordingly. The wording in chapter 5.2 was changed according to the recommendations.

The marked changes can be found below. 


\title{
Critical evaluation of the small punch test as a screening procedure for mechanical properties
}

E. Altstadt ${ }^{1 *}$, H.E. Ge ${ }^{2}$, V. Kuksenko ${ }^{2}$, M. Serrano ${ }^{3}$, M. Houska ${ }^{1}$, M. Lasan ${ }^{4}$, M. Bruchhausen ${ }^{5}$, J.-M. Lapetite ${ }^{5}$, Y. Dai ${ }^{2}$

${ }^{1}$ Helmholtz-Zentrum Dresden - Rossendorf (HZDR), Dresden, Germany

${ }^{2}$ Paul-Scherrer-Institut, Villigen, Switzerland

${ }^{3}$ Centro de Investigaciones Energéticas, Medioambientales y Tecnológicas (CIEMAT), Madrid, Spain

${ }^{4}$ Research Centre Rez (RCR), Husinec, Czech Republic

${ }^{5}$ Joint Research Centre, Institute of Energy and Transport (JRC-IET), Petten, Netherlands

* Corresponding author: e.altstadt@hzdr.de, +49-351-2602276, D-01328 Dresden, Bautzner Landstrasse 400

\begin{abstract}
For quick sereening of material properties, it is important to provide simple experimental test techniques to address specific aspects of material properties. Within work package 2 of the Euratom FP7 MATTER project, a small punch test collective exercise was conducted to eritically evaluate the potential of this technique for the characterisation of irradiation hardening and embrittlement. The ferritic-martensitic 9\%Cr-steel T91 was used. Several data sets were produced for two major specimen geometries by different European laboratories. The reproducibility and scatter of results expressed by coefficient of variation for the total and plastic energy, the elastic plastic transition load, the maximum load and the displacement at maximum load was analysed. The largest scatter was observed for the elastic plastic transition toad and for the plastic energy. Correlations for the estimation of tensile properties were shown to be device dependent. The estimations of the ductile to brittle transition temperatures are in a good agreement in cases of identical main geometrical parameters. The SP tests of neutron irradiated T91 (dose between 2.3 and 4 dpa) showed that the equivalent Charpy transition temperature shifts obtained from SP tests are in very good agreement with KLST based values. Thus the small punch test is an appropriate tool for the screening of the neutron irradiation induced embrittlement. We also observed a signifieant effect of irradiation on the recalculated yield stress and ultimate tensile strength. In comparison with tensile data, the irradiation induced hardening was underestimated. The small punch test is less appropriate for the sereening of hardening (yield stress increase) than it is for embrittlement.

Within a collective exercise, a systematic and statistically based analysis of the repeatability and device dependence of small punch test results was performed. An unirradiated ferriticmartensitic steel T91 was selected for this. The test results allowed an evaluation of accuracy and reliability of material properties extracted from load-displacement-based and energybased parameters. In a second step, neutron irradiated T91 with doses of 2.3 and 4 dpa was investigated in the temperature range $-165^{\circ} \mathrm{C}$ to $300^{\circ} \mathrm{C}$. The effects of test temperature and irradiation on the load-displacement curves and on the derived parameters were analysed. It was found that the small punch test is well suited for estimation of neutron embrittlement in cases of small amounts of available material or high activity. The preferred procedure for that purpose was specified.
\end{abstract}

\section{Introduction}

Small specimen test technologies have long been recognized as a supportive means for the development and monitoring of structural materials for nuclear components [1]. The small punch (SP) test [2-11] received much attraction and widespread use. However, details of the sample preparation, device and sample geometry as well as testing procedure and analysis may differ from laboratory to laboratory. Within the Euratom FP7-Project MATTER

(MATerials TEsting and Rules), work package 2 was dedicated to the development of 
screening test procedures for mechanical properties. Screening procedures are intended to provide approximate data of the properties with as small amounts of material as possible and thus allowing a quick evaluation of ageing mechanisms such as neutron irradiation induced hardening and embrittlement or liquid metal embrittlement. Amongst others, the small punch (SP) test was selected as a testing method for screening.

The SP test is well suited to investigate irradiation effects, since the amount of material needed is small and thereby the total activity of specimens is much lower than for classical mechanical and fracture mechanics tests. For example the mass and thus the activity ratio between a SP standard specimen $\left(\varnothing 8 \times 0.5 \mathrm{~mm}^{3}\right)$ and a full-sized Charpy specimen

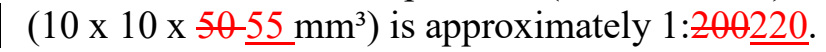

The ductile to brittle transition temperature (DBTT) can be extracted from the SP tests. From a single load-deflection curve one can calculate the energy $E_{S P}$ needed to deform and crack the SP sample. Doing this for different temperatures, the $\mathrm{E}_{\mathrm{SP}}(\mathrm{T})$ curve can be constructed. Usually this curve is assembled from two fits, the first one describing the brittle and transition regime and the second one the ductile regime. The intersection of the two curves marks the maximum of the fitted $\mathrm{E}_{\mathrm{SP}}(\mathrm{T})$ course, $\mathrm{E}_{\max }$. The $\mathrm{SP}$ transition temperature $\mathrm{T}_{\mathrm{SP}}$ is defined as temperature where $\mathrm{E}_{\mathrm{SP}}=0.5^{*}\left(\mathrm{E}_{\max }-\mathrm{E}_{\min }\right)$ holds $[2,3]$. A linear correlation with the Charpy transition temperature $\mathrm{T}_{\mathrm{CVN}}$ is proposed in $[4,5]$ :

$$
\mathrm{T}_{\mathrm{SP}}=\alpha \cdot \mathrm{T}_{\mathrm{CVN}}
$$

where absolute temperatures have to be used. The factor $\alpha$ was found to be $0.32 \ldots 0.34$ for 2.25Cr-1Mo steels and $1 \mathrm{Cr}-0.5 \mathrm{Mo}$ steels respectively, based on SP specimens of $0.5 \mathrm{~mm}$ thickness and a punch ball diameter of $2.4 \mathrm{~mm}$. However, other results [6,7] give rise to the assumption that the factor $\alpha$ depends on both the SP geometry and the material. Kameda provided a rationale for the linear relationship Eq. (1) by means of a kinetic model for ductilebrittle fracture mode transition considering also the strain rate effect [8]:

$$
\alpha=\frac{\mathrm{T}_{\mathrm{SP}}}{\mathrm{T}_{\mathrm{CVN}}}=\frac{\left\{\ln \left[\left(\frac{\mathrm{V}_{\mathrm{S}} \mathrm{F}_{\mathrm{S}}}{\mathrm{V}_{\mathrm{t}} \mathrm{F}_{\mathrm{t}}}\right)\left(\frac{\dot{\varepsilon}_{0}}{\dot{\varepsilon}}\right)^{2}\right]\right\}_{\mathrm{CVN}}}{\left\{\ln \left[\left(\frac{\mathrm{V}_{\mathrm{S}} \mathrm{F}_{\mathrm{S}}}{\mathrm{V}_{\mathrm{t}} \mathrm{F}_{\mathrm{t}}}\right)\left(\frac{\dot{\varepsilon}_{0}}{\dot{\varepsilon}}\right)^{2}\right]\right\}_{\mathrm{SP}}}
$$

where $\mathrm{V}$ and $\mathrm{F}$ are fracture volume and micro-crack density respectively, and the subscripts $\mathrm{s}$ and $\mathrm{t}$ indicate shear and tension. Based on results for ferritic-martensitic steels, the factor was obtained as $\alpha \approx 0.4$.

The SP test has also been used to estimate hardening, i.e. increase of the yield stress (YS). A linear correlation was proposed for the YS

$$
\mathrm{R}_{\mathrm{p} 02}=\beta_{\mathrm{YS}} \cdot \mathrm{F}_{\mathrm{e}} / \mathrm{h}^{2}
$$

with $\mathrm{h}$ being the initial specimen thickness, $\mathrm{F}_{\mathrm{e}}$ the SP load at the onset of plastic flow and $\beta_{\mathrm{YS}}$ an empirical factor. Kameda and Mao [9] found $\beta_{Y S}=0.36$ for specimen thicknesses of $0.25 \mathrm{~mm}$ and $0.5 \mathrm{~mm}$. In [10] the correlation was underpinned by finite element simulations 
of SP tests. Two different correlations were proposed for the estimation of the ultimate tensile strength (UTS) [10,11]:

$$
\begin{aligned}
& \mathrm{R}_{\mathrm{m}}=\beta_{\mathrm{UTS}} \cdot \mathrm{F}_{\mathrm{m}} / \mathrm{h}^{2} \\
& \mathrm{R}_{\mathrm{m}}=\beta_{\mathrm{UTS}} \cdot \mathrm{F}_{\mathrm{m}} /\left(\mathrm{h} \cdot \mathrm{u}_{\mathrm{m}}\right)
\end{aligned}
$$

with $\mathrm{F}_{\mathrm{m}}$ being the maximum load and $\mathrm{u}_{\mathrm{m}}$ the corresponding displacement.

Detailed analyses of stress and strain in the SP disc have been performed by means of analytical elastic-plastic modelling $[12,13]$ and by finite element calculations $[10,14,15]$. A combination of finite element modelling, SP testing and neural networks was used to identify the parameters of the Gurson-Tvergaard-Needleman model for ductile damage [14] and of the Beremin model for brittle fracture [15].

In this paper, we present the results of a SP test collective exercise with unirradiated T91 steel. This exercise aimed at the analysis of scatter, reproducibility and device dependence of characteristic parameters extracted from SP tests.

Another focus of the paper is put on the investigation of neutron irradiation induced hardening and embrittlement by means of the SP test. The usefulness of the above mentioned correlations for screening of hardening and embrittlement (Eqs. 1-4) is evaluated.

\section{Material}

All tests reported in this paper are related to the $9 \mathrm{Cr}$ ferritic martensitic steel $\mathrm{T} 91$ as defined in the ASTM standard A387-Ed99 (Grade 91 Class 2 / S50460). Two heats of this material were investigated. The first heat was characterised in the FP6 project EUROTRANS (project domain 4 - DEMETRA). This heat was produced by ARCELOR and is referred to as "T91-DEM" in this paper. It was used for the SP collective exercise. The second heat was produced by UGINE, France. It was characterised within the FP5 project SPIRE. This heat is referred to as "T91-SPI" in this paper. A neutron irradiation experiment at the reactor BR2 in Mol, Belgium, was part of the SPIRE project. The T91-SPI heat was used for the evaluation of irradiation induced hardening and embrittlement. The chemical compositions are listed in Table 1 and heat treatments and product forms in Table 2.

\begin{tabular}{|c|c|c|c|c|c|c|c|c|c|c|c|c|c|c|c|}
\hline & $\mathrm{C}$ & $\mathrm{Si}$ & $\mathrm{V}$ & $\mathrm{Cr}$ & $\mathrm{Mn}$ & $\mathrm{Ni}$ & Mo & $\mathrm{N}$ & $\mathrm{Al}$ & $\mathrm{P}$ & $\mathrm{S}$ & $\mathrm{Ti}$ & $\mathrm{Cu}$ & $\mathrm{Nb}$ & W \\
\hline T91-DEM & 0.1025 & 0.22 & 0.21 & 8.99 & 0.38 & 0.11 & 0.89 & 0.0442 & 0.0146 & 0.021 & 0.0004 & 0.0034 & 0.06 & 0.06 & 0.01 \\
\hline T91-SPI & 0.099 & 0.32 & 0.24 & 8.8 & 0.43 & 0.24 & 0.96 & 0.03 & $<0.01$ & 0.02 & 0.004 & $<0.005$ & 0.05 & 0.06 & $<0.01$ \\
\hline
\end{tabular}

Table 1: Composition the T91 heats (wt\%)

\begin{tabular}{lll}
\multicolumn{2}{l}{ Table 2: Product form and heat treatment } & \\
\hline Heat & Product form & Heat treatment \\
\hline T91-DEM & $\begin{array}{l}\text { hot rolled plate } \\
\text { thickness } 15 \mathrm{~mm}\end{array}$ & $\begin{array}{l}\text { normalization } 1050^{\circ} \mathrm{C} / 15 \mathrm{~min} \\
\text { tempering } 770{ }^{\circ} \mathrm{C} / 45 \mathrm{~min}\end{array}$ \\
\hline T91-SPI & $\begin{array}{l}\text { hot rolled plate } \\
\text { thickness } 15 \mathrm{~mm}\end{array}$ & $\begin{array}{l}\text { normalization } 1040{ }^{\circ} \mathrm{C} / 60 \mathrm{~min} \\
\text { tempering } 760{ }^{\circ} \mathrm{C} / 60 \mathrm{~min}\end{array}$ \\
\hline
\end{tabular}

The temperature dependent yield stress and tensile strength are shown in Figure 1 (T91-DEM) Figure 2 (T91-SPI). The data were taken from [16] and [17] respectively. The temperature fits for $\mathrm{R}_{\mathrm{p} 02}$ and $\mathrm{R}_{\mathrm{m}}$ of T91-DEM are given by Eq. (5):

$$
\begin{aligned}
& \mathrm{R}_{\mathrm{p} 02}(\mathrm{MPa})=588-0.165 \cdot \mathrm{T}(\mathrm{K})+1248 \cdot \exp [-0.013 \cdot \mathrm{T}(\mathrm{K})] \\
& \mathrm{R}_{\mathrm{m}}(\mathrm{MPa})=713-0.205 \cdot \mathrm{T}(\mathrm{K})+995 \cdot \exp [-0.011 \cdot \mathrm{T}(\mathrm{K})]
\end{aligned}
$$


For T91-SPI the temperature fits are given by Eq. (6):

$$
\begin{aligned}
& \mathrm{R}_{\mathrm{p} 02}(\mathrm{MPa})=602-0.241 \cdot \mathrm{T}(\mathrm{K})+51633 \cdot \exp [-0.05 \cdot \mathrm{T}(\mathrm{K})] \\
& \mathrm{R}_{\mathrm{m}}(\mathrm{MPa})=794-0.398 \cdot \mathrm{T}(\mathrm{K})+43321 \cdot \exp [-0.05 \cdot \mathrm{T}(\mathrm{K})]
\end{aligned}
$$

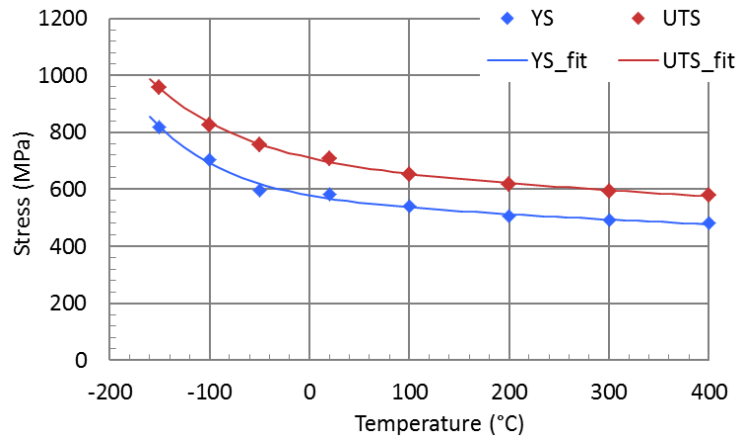

Figure 1: Yield strength and ultimate tensile strength vs. temperature for T91-DEM [16]

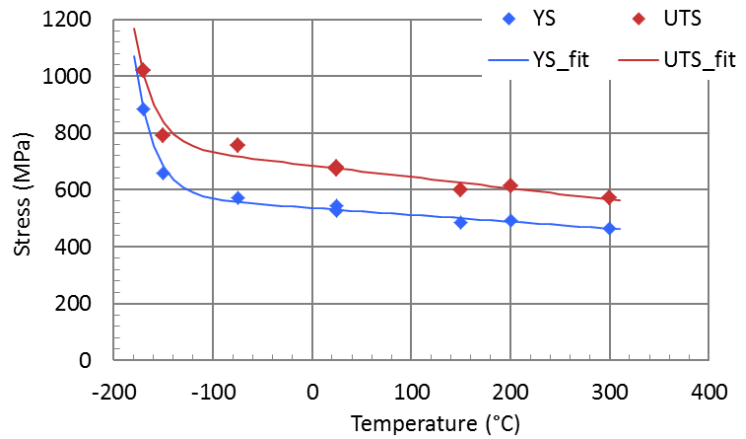

Figure 2: Yield strength and ultimate tensile strength vs. temperature for T91-SPI [17]

For T91-SPI, tensile tests results at $200{ }^{\circ} \mathrm{C}$ of the unirradiated and neutron irradiated

\begin{tabular}{|c|c|c|c|c|c|}
\hline $\begin{array}{l}\text { Dose } \\
\text { (dpa) }\end{array}$ & $\begin{array}{l}\text { Yield stress, } \mathrm{R}_{\mathrm{p} 02} \\
(\mathrm{MPa})\end{array}$ & $\begin{array}{l}\text { UTS, } R_{m} \\
(\mathrm{MPa})\end{array}$ & $\begin{array}{l}\text { Uniform strain } \\
(\%)\end{array}$ & $\begin{array}{l}\text { Fracture strain } \\
(\%)\end{array}$ & $\begin{array}{l}\text { area reduction, } \mathrm{Z} \\
(\%)\end{array}$ \\
\hline$\overline{0}$ & 494 & 616 & 6 & 19 & 72 \\
\hline 2.95 & 835 & 838 & 2 & 12 & 79 \\
\hline 4.36 & 835 & 840 & 2 & 11 & 65 \\
\hline
\end{tabular}
conditions are given in Table 3 [17].

The ductile to brittle transition temperatures obtained by means of KLST specimens are listed in Table 4. There was no significant anisotropy [16,17]. According to a work of Klausnitzer [18] the ductile-to-brittle transition temperature obtained from KLST tests ( $\mathrm{T}_{\mathrm{KLST}}$ ) can be converted into standard transition temperatures obtained by Charpy specimens $\left(\mathrm{T}_{\mathrm{CVN}}\right)$ by the following correlation:

$$
\mathrm{T}_{\mathrm{CVN}}=\mathrm{T}_{\mathrm{KLST}}+65 \mathrm{~K}
$$

\begin{tabular}{|c|c|c|c|c|}
\hline Heat & Dose (dpa) & USE (J) & $\mathrm{T}_{\mathrm{KLST}}\left({ }^{\circ} \mathrm{C}\right)$ & $\mathrm{T}_{\mathrm{CVN}}\left({ }^{\circ} \mathrm{C}\right)$, Eq. $(7)$ \\
\hline T91-DEM & 0 & 8.7 & -98 & -33 \\
\hline T91-SPI & 0 & 6.5 & -73 & -8 \\
\hline T91-SPI & 2.43 & 6.0 & 35 & +100 \\
\hline T91-SPI & 3.58 & 6.1 & 57 & +122 \\
\hline
\end{tabular}




\section{Experimental}

\subsection{SP test collective exercise}

Five laboratories (labelled as Lab1 to Lab5) participated in the collective exercise. The heat T91-DEM was used for this exercise. Two basic geometries were considered for the manufacturing of the SP specimens: small geometry (specimen thickness $0.25 \mathrm{~mm}$ ) and standard geometry (specimen thickness $0.5 \mathrm{~mm}$ ). Further geometrical details are summarized in Figure 3 and Table 5. The specimen is assumed to be fully clamped so that the outer contour of the specimens (square or round) has no effect. The test devices of the different labs for the standard geometry have basically the same dimensions. Only the lower die edge is differently shaped (edge radius $0.5 \mathrm{~mm}$ vs. chamfer $0.2 \mathrm{~mm} \mathrm{x} 45^{\circ}$ ). For the small geometry, there are additionally differences in the lower die diameter.

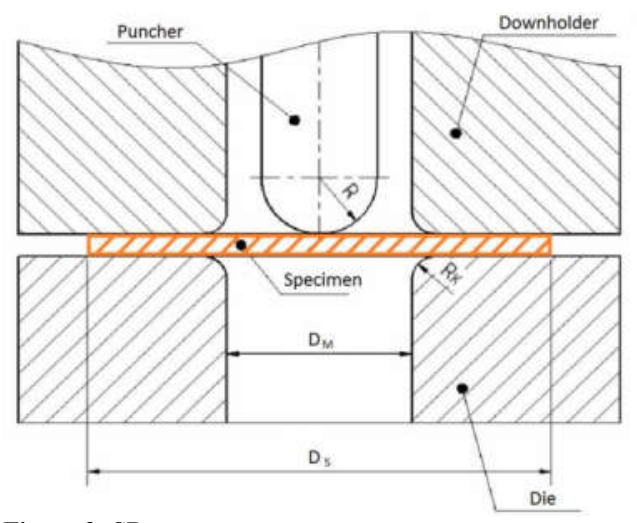

Figure 3: SP test geometry

Table 5: Main geometrical parameters of the test devices and specimens

\begin{tabular}{lll}
\hline & Small geometry & Standard geometry \\
\hline Specimen thickness $\mathrm{h}(\mathrm{mm})$ & 0.25 & 0.5 \\
\hline Lower die diameter $\mathrm{D}_{\mathrm{M}}(\mathrm{mm})$ & $1.75(\mathrm{Lab} 2), 1.5(\mathrm{Lab} 1, \mathrm{Lab} 3)$ & 4.0 \\
\hline \multirow{2}{*}{ Edge radius $\mathrm{R}_{\mathrm{K}}(\mathrm{mm})$ or chamfer } & $0.2(\mathrm{Lab} 1), 0.25(\mathrm{Lab} 2)$, & $0.2(\mathrm{Lab} 1), 0.5(\mathrm{Lab} 2)$, \\
& $0.2 \times 45^{\circ}(\mathrm{Lab} 3)$ & $0.2 \times 45^{\circ}(\mathrm{Lab} 3, \mathrm{Lab} 4, \mathrm{Lab} 5)$ \\
\hline \multirow{2}{*}{ Puncher radius $\mathrm{R}(\mathrm{mm})$} & 0.5 & 1.25 \\
\hline \multirow{2}{*}{ Specimen size, $\mathrm{mm}$} & $\varnothing 3 \times 0.25(\mathrm{Lab} 1, \mathrm{Lab3})$ & $\varnothing 8 \times 0.5(\mathrm{all}$ but Lab2) \\
& $3.5 \times 3.5 \times 0.25(\mathrm{Lab} 2)$ & $10 \times 10 \times 0.5(\mathrm{Lab} 2)$ \\
\hline
\end{tabular}

The specimens were cut to a thickness of $0.4 \mathrm{~mm}$ (small geometry) or $0.6 \mathrm{~mm}$ (standard geometry) respectively by means of electrical discharge machines (EDM) and subsequent ground with grit 1200 to final thickness. The individual final thickness of each specimen was protocolled in the test reports of the labs. The maximum accepted thickness tolerance was $0.5 \%$ of the nominal thickness [5]. All tests were performed at a displacement rate of $0.3 \mathrm{~mm} / \mathrm{min}$. The requested tolerance for the measurement of the test temperature was $\pm 3 \mathrm{~K}$.

Five tests were performed at RT and five tests at $300{ }^{\circ} \mathrm{C}$ for both geometries. For each of the two temperature levels an average load-displacement curve was to be calculated including the scatter band. Additional tests were performed in the temperature range $-195 \ldots 20^{\circ} \mathrm{C}$ for the evaluation of the DBTT. In total, each lab conducted between 24 and 55 SP tests per geometry. Three of the labs (Lab1, Lab2 and Lab3) conducted tests for both geometries while the others conducted the tests for the standard geometry only.

The YS and UTS are estimated by means of Eqs. (2) and (3). The transition load $F_{\mathrm{e}}$ is determined by a bilinear fit procedure according to code of practice [5], cf. Figure 4 . We used $\mathrm{u}_{\mathrm{B}}=0.5 \mathrm{~mm}$ for the standard geometry and $\mathrm{u}_{\mathrm{B}}=0.2 \mathrm{~mm}$ for the small geometry. The 
parameter $\mathrm{u}_{\mathrm{A}}$ was optimized in such a way that the sum of square errors of both regression lines is minimized.

In order to estimate the coefficient $\beta_{\mathrm{YS}}$, the values of $\mathrm{F}_{\mathrm{e}} / \mathrm{h}^{2}$ were plotted against the YS calculated by Eq. (5a) for the according test temperature. As an example the plot of Lab2 for the standard geometry is shown in Figure 5. Likewise the UTS obtained from Eq. (5b) and the values $\mathrm{F}_{\mathrm{m}} /\left(\mathrm{h} \cdot \mathrm{u}_{\mathrm{m}}\right)$ or $\mathrm{F}_{\mathrm{m}} / \mathrm{h}^{2}$ respectively were used to obtain the coefficient $\beta_{\mathrm{UTS}}$.
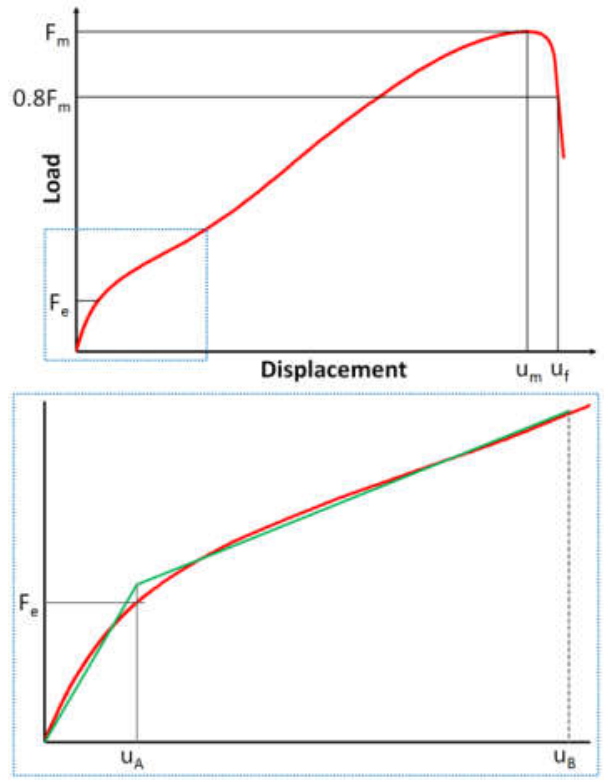

Figure 4: Characteristic parameters of the SP load-displacement curve [5]

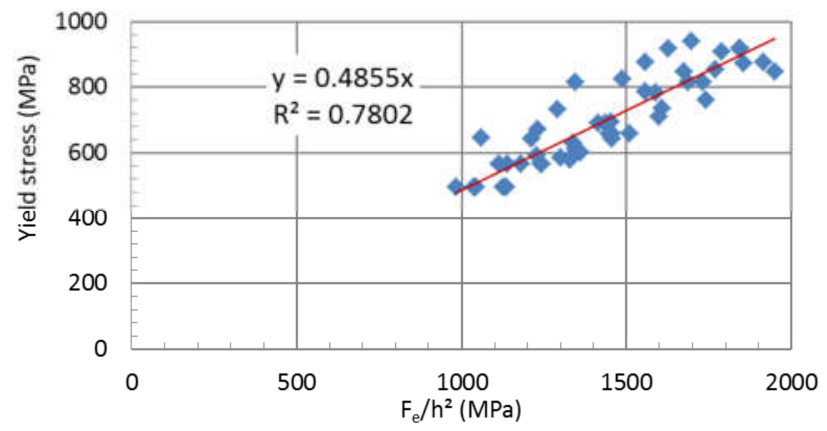

Figure 5: Regression line between $R_{p 02}$ and $F_{\mathrm{e}} / h^{2} ; 10 \times 10 \times 0.5$ samples, Lab2, T91-DEM

The ductile to brittle transition temperature was evaluated from the temperature dependent SP energies. The total SP energy is the area under the load displacement curve. The energy up to the displacement at maximum load $\mathrm{u}_{\mathrm{m}}$ was used. The plastic energy is calculated by:

$$
\mathrm{E}_{\mathrm{SP}, \mathrm{pl}}=\mathrm{E}_{\mathrm{SP}, \mathrm{to}}-0.5 \cdot \mathrm{F}_{\mathrm{m}}^{2} \cdot \mathrm{u}_{\mathrm{A}} / \mathrm{F}_{\mathrm{A}}
$$

where $\left(\mathrm{u}_{\mathrm{A}}, \mathrm{F}_{\mathrm{A}}\right)$ is the intersection point of the bilinear fit for the determination of $\mathrm{F}_{\mathrm{e}}(\mathrm{cf}$. Figure 4).

A two-curve fitting procedure was applied for the $\mathrm{E}_{\mathrm{SP}}(\mathrm{T})$ dependence. The fitting curves are both described by the following exponential equation: 


$$
E_{b / d}(T)=A_{b / d}+B_{b / d} \cdot \exp \left[C_{b / d} \cdot T\right]
$$

where the index "b" refers to the brittle region and the index " $d$ " to the ductile region. The absolute temperature is used. A least square procedure was used to determine the coefficients $A_{b}, B_{b}, C_{b}, A_{d}, B_{d}$, and $C_{d}$. The intersection of the two curves marks the maximum of the fitted $E_{S P}(T)$ dependency, $E_{\max }$, while the minimum energy is given by $E_{\min }=A_{b}+B_{b}$ (i.e.

$\mathrm{T}=0 \underline{\mathrm{K}})$. The SP transition temperature $\mathrm{T}_{\mathrm{SP}}$ is defined as temperature where $\mathrm{E}_{\mathrm{b}}\left(\mathrm{T}_{\mathrm{SP}}\right)=\left(\mathrm{E}_{\min }+\mathrm{E}_{\max }\right) / 2$ holds. As an example, Figure 6 shows the $\mathrm{E}_{\mathrm{SP}}(\mathrm{T})$ plot of Lab2 for the standard geometry.

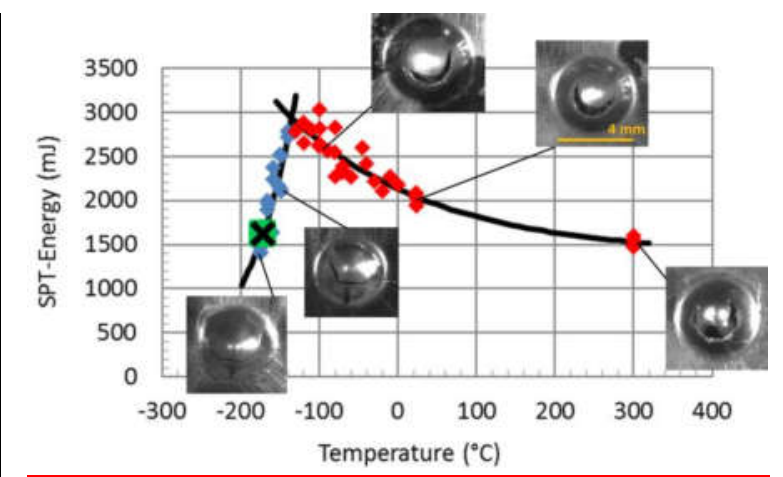

Figure 6: Determination of $T_{\mathrm{SP}}$ using the total energy up $u_{\mathrm{m}}$, T91-DEM, Lab2, standard geometry, $\mathrm{T}_{\mathrm{SP}}=-172{ }^{\circ} \mathrm{C}$ (green diamondblack $\mathrm{X}$ )

The different fracture modes are also shown. One circular crack occurs during ductile failure whilst the brittle failure is characterised by several edged cracks. Other authors used the macroscopic appearance of the cracks as an additional screening criterion for ductility of the material $[19,20]$.

\subsection{SP tests for the evaluation of irradiation effects}

Unirradiated broken Charpy samples of the T91-SPI heat and neutron irradiated broken KLST samples of this material were employed for the manufacturing of the SP samples (cf. Table 6).

| Table 6: Specimen codes and irradiation conditions of broken Charpy and KLST specimens used for the manufacturing of SP testT samples

\begin{tabular}{lllll}
\hline Specimen code & Specimen type & Neutron dose $(\mathrm{dpa})$ & $\begin{array}{l}\text { Irradiation temperature } \\
\left({ }^{\circ} \mathrm{C}\right)\end{array}$ & Codes of SP specimens \\
\hline T91-17 & Charpy & 0 & - & $01,02, \ldots, 39$ \\
\hline KR (one half) & KLST & 2.31 & 200 & KR01 .. KR11 \\
\hline KS (both halves) & KLST & 2.31 & 200 & KS01 .. KS22 \\
\hline MA (one half) & KLST & 2.31 & 200 & MA01 ... MA11 \\
\hline HE (both halves) & KLST & 3.99 & 200 & HE01 .. HE2 21 \\
\hline HH (both halves) & KLST & 3.99 & 200 & HH01 ... HH21 \\
\hline
\end{tabular}

The neutron irradiation had been performed in the framework of the SPIRE project [17]. The material was irradiated at $(200 \pm 5)^{\circ} \mathrm{C}$ in the BR2 reactor (Mol, Belgium) using the MISTRAL irradiation rig for 6 cycles.

The specimen geometry for the SP tests is $4 \times 3 \times 0.3 \mathrm{~mm}^{3}$. Slices from the KLST specimens were taken by EDM in a hot cell. The samples were not ground or polished. To improve the surface quality, a post cut was applied. A total number of 39 specimens were manufactured from the unirradiated material and 76 specimens from the irradiated material. The test temperatures ranged from $-165^{\circ} \mathrm{C}$ to $+303{ }^{\circ} \mathrm{C}$. All tests including those for the unirradiated condition were performed in the hot cell laboratory of Lab2 in order to exclude any effects 
from the testing device when evaluating the irradiation effect. As an example selected loaddisplacements curves of the neutron dose 2.31 dpa are shown in Figure 7.

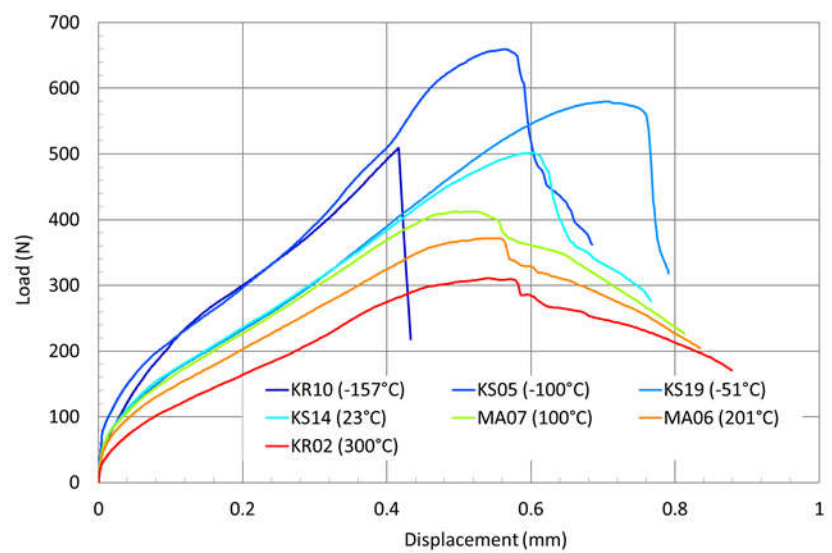

Figure 7: Load-displacement curves at selected temperatures, 4 × 3 x 0.3, T91-SPI, 2.31 dpa

\section{Results}

\subsection{SP test collective exercise}

As a first step, we compare the load-displacement curves of different labs in order to evaluate the effect of the individual test devices. Figure 8 shows the mean curves out of five tests at $300{ }^{\circ} \mathrm{C}$. The averaging procedure includes the following steps: i) normalisation of the loads and displacements to the range $[0,1]$ for each data series; ii) calculate the normalised path lengths of the data points for each series; iii) calculate the arithmetic mean of the data points which have the same relative paths length; iv) apply steps $\mathrm{i}-$ iii for the displacement ranges $\left[0, \mathrm{u}_{\mathrm{m}}\right]$ and $\left[\mathrm{u}_{\mathrm{m}}, \mathrm{u}_{\mathrm{f}}\right]$ section by section.

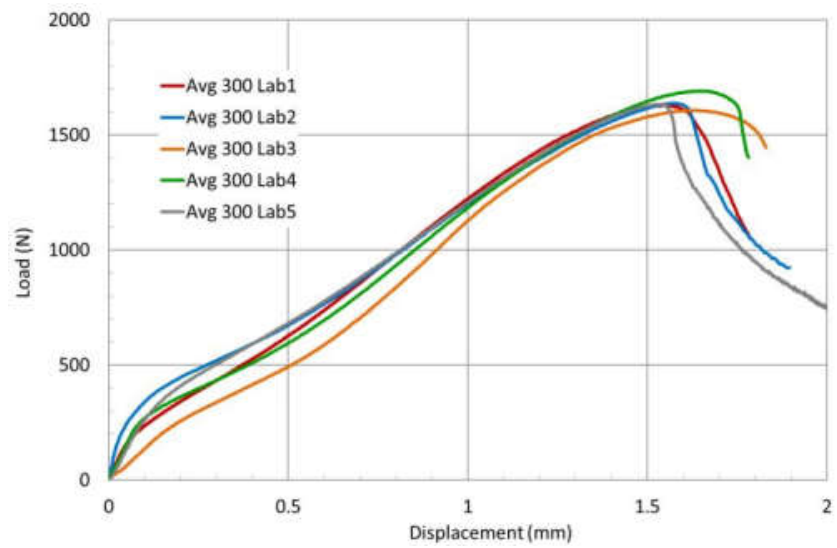

Figure 8: Comparison of load-displacement curves of tests at $300{ }^{\circ} \mathrm{C}$; averaged curves out of 5 tests; T91-DEM specimen thickness $0.5 \mathrm{~mm}$

While the maximum loads are in a quite good agreement, the curves differ in the slope of the elastic part. This results also in significant differences in the range up to $1 \mathrm{~mm}$ displacement. The displacements $\mathrm{u}_{\mathrm{m}}$ at maximum load agree reasonably. A detailed analysis of the SP results is given in Table 7 for room temperature and in Table 8 for $\mathrm{T}=300{ }^{\circ} \mathrm{C}$. The mean values $\mu$ of the parameters $\mathrm{E}_{\mathrm{to}}, \mathrm{E}_{\mathrm{pl}}, \mathrm{F}_{\mathrm{e}}, \mathrm{F}_{\mathrm{m}}$ and $\mathrm{u}_{\mathrm{m}}$ were calculated from the five individual tests for each lab. The relative error for the parameters is expressed by means of the coefficient of variation, i.e. the ratio of standard deviation $\sigma$ and mean $\mu\left(c_{v}=\sigma / \mu\right)$. The values in the last row ("All labs") were calculated from the mean values $\mu$ of Lab1 to Lab5. Thus, the average $c_{v}$ is not the arithmetic mean of the $c_{v}$ values of the labs. The $c_{v}$-values of Lab1 - Lab5 
indicate the in-house repeatability of the parameters using one and the same SP device, while the $\mathrm{c}_{\mathrm{v}}$-values in the "All labs" row characterise the inter-laboratory reproducibility (i.e. the effect of different devices) on the parameters. Low $\mathrm{c}_{\mathrm{v}}$-values indicate a good repeatability and a low device dependence (good reproducibility) respectively. It should be noted, that the main geometrical parameters of the different SP test set-ups are identical (Table 5), some minor differences like chamfer and edge radius of the lower die hole or the outer shape of the specimen are not believed to cause significant differences in the SP results.

\begin{tabular}{|c|c|c|c|c|c|c|c|c|c|c|}
\hline & \multicolumn{2}{|c|}{$\mathrm{E}_{\text {to }}$ up to $\mathrm{u}_{\mathrm{m}}$} & \multicolumn{2}{|c|}{$E_{p l}$ up to $u_{m}$} & \multicolumn{2}{|c|}{$\mathrm{F}_{\mathrm{e}}$} & \multicolumn{2}{|c|}{$\mathrm{F}_{\mathrm{m}}$} & \multicolumn{2}{|c|}{$\mathrm{u}_{\mathrm{m}}$} \\
\hline & $\mu(\mathrm{mJ})$ & $\mathrm{c}_{\mathrm{v}}(\%)$ & $\mu(\mathrm{mJ})$ & $\mathrm{c}_{\mathrm{v}}(\%)$ & $\mu(\mathrm{N})$ & $\mathrm{c}_{\mathrm{v}}(\%)$ & $\mu(\mathrm{N})$ & $\mathrm{c}_{\mathrm{v}}(\%)$ & $\mu(\mathrm{mm})$ & $\mathrm{c}_{\mathrm{v}}(\%)$ \\
\hline Lab1 & 1849 & 3.6 & 1336 & 6.6 & 251 & 1.9 & 1898 & 2.6 & 1.63 & 1.2 \\
\hline Lab2 & 2017 & 3.4 & 1626 & 3.1 & 296 & 4.9 & 1940 & 1.3 & 1.72 & 2.1 \\
\hline Lab3 & 1795 & 2.1 & 981 & 10.5 & 241 & 7.4 & 1916 & 1.4 & 1.64 & 1.7 \\
\hline Lab4 & 1715 & 4.1 & 1181 & 6.6 & 335 & 6.8 & 1930 & 1.8 & 1.47 & 2.6 \\
\hline Lab5 & 2006 & 1.9 & 1257 & 3.4 & 394 & 3.8 & 1982 & 2.0 & 1.71 & 1.3 \\
\hline All labs & 1876 & 7.1 & 1276 & 18.5 & 303 & 20.7 & 1940 & 1.6 & 1.63 & 6.1 \\
\hline
\end{tabular}

Table 8: Mean value $\mu$ and coefficient of variation $c_{v}$ of results of SP tests at $300{ }^{\circ} \mathrm{C}$, standard geometry

\begin{tabular}{|c|c|c|c|c|c|c|c|c|c|c|}
\hline & \multicolumn{2}{|c|}{$\mathrm{E}_{\text {to }}$ up to $\mathrm{u}_{\mathrm{m}}$} & \multicolumn{2}{|c|}{$\mathrm{E}_{\mathrm{pl}}$ up to $\mathrm{u}_{\mathrm{m}}$} & \multicolumn{2}{|c|}{$\mathrm{F}_{\mathrm{e}}$} & \multicolumn{2}{|c|}{$\mathrm{F}_{\mathrm{m}}$} & \multicolumn{2}{|c|}{$\mathrm{u}_{\mathrm{m}}$} \\
\hline & $\mu(\mathrm{mJ})$ & $\mathrm{c}_{\mathrm{v}}(\%)$ & $\mu(\mathrm{mJ})$ & $\mathrm{c}_{\mathrm{v}}(\%)$ & $\mu(\mathrm{N})$ & $\mathrm{c}_{\mathrm{v}}(\%)$ & $\mu(\mathrm{N})$ & $\mathrm{c}_{\mathrm{v}}(\%)$ & $\mu(\mathrm{mm})$ & $\mathrm{c}_{\mathrm{v}}(\%)$ \\
\hline Lab1 & 1446 & 4.9 & 1031 & 6.9 & 213 & 7.1 & 1633 & 3.7 & 1.54 & 1.3 \\
\hline Lab2 & 1533 & 3.4 & 1279 & 5.8 & 266 & 6.1 & 1638 & 2.3 & 1.58 & 0.9 \\
\hline Lab3 & 1422 & 2.1 & $654^{1)}$ & $7.5^{1)}$ & 219 & 12.3 & 1608 & 2.9 & 1.62 & 1.8 \\
\hline Lab4 & 1592 & 2.5 & 1131 & 13.4 & 251 & 8.1 & 1692 & 1.8 & 1.65 & 2.3 \\
\hline Lab5 & 1457 & 3.6 & 944 & 9.3 & 321 & 7.3 & 1634 & 2.7 & 1.53 & 0.8 \\
\hline All labs & 1490 & 4.7 & 1012 & 22.4 & 258 & 15.7 & 1641 & 1.9 & 1.58 & 3.2 \\
\hline
\end{tabular}

${ }^{1)}$ based on 3 tests instead of 5

Figure 9 shows averaged load-displacement curves of tests of Lab1 - Lab3 at $300{ }^{\circ} \mathrm{C}$ using samples of $0.25 \mathrm{~mm}$ thickness. The larger diameter of the lower die hole in the case of Lab2 (cf. Table 5) gives rise to a lower maximum load and a higher displacement $\mathrm{u}_{\mathrm{m}}$ at maximum load. Detailed results of the SP tests with small specimens at $300{ }^{\circ} \mathrm{C}$ are given in Table 9 . However, we can only evaluate the repeatability of results for the individual labs. The calculation of average $\mathrm{c}_{\mathrm{v}}$-values is not meaningful because we have results of only three labs and because of the difference in the lower die diameter as a main geometrical parameter.

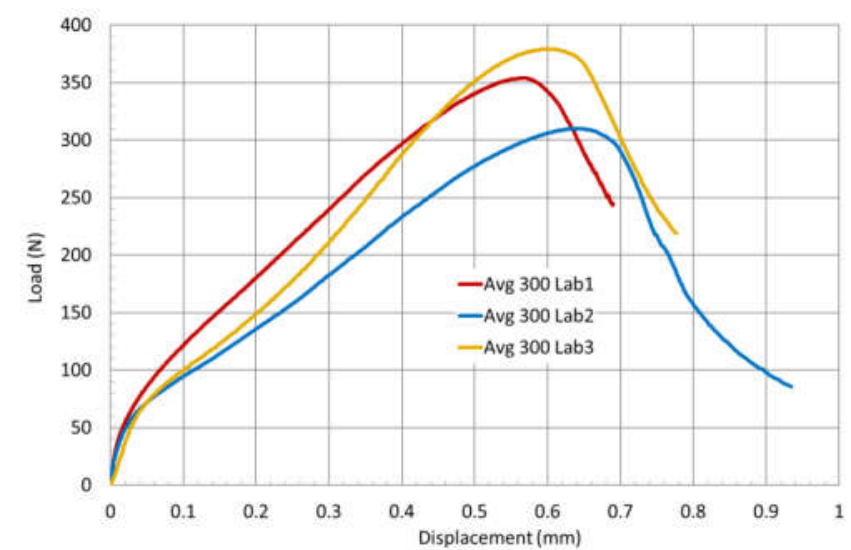

Figure 9: Comparison of load-displacement curves of tests at $300{ }^{\circ} \mathrm{C}$; averaged curves out of 5 tests; T91-DEM specimen thickness $0.25 \mathrm{~mm}$

Table 9: Mean value $\mu$ and coefficient of variation $c_{v}$ of results of $S P$ tests at $300{ }^{\circ} \mathrm{C}$, small geometry

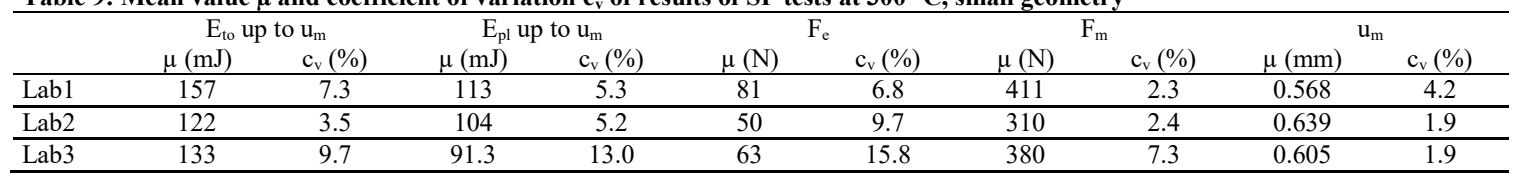


Three different geometrical configurations were used to correlate $F_{e} / h^{2}$ with $R_{p 02}$. As for $R_{m}$ it is not clear from the literature, whether it should be correlated with $F_{m} /\left(u_{m} \cdot h\right)$ or with $F_{m} / h^{2}$. Therefore both correlations are given (Table 10).

Table 10: Correlations of $R_{p 02}$ with $F_{e}$ and of $R_{m}$ with $F_{m}$

\begin{tabular}{llllll}
\hline & $\begin{array}{l}\text { Lab1 data } \\
\text { Standard geometry }\end{array}$ & $\begin{array}{l}\text { Lab2 data } \\
\text { Standard geometry }\end{array}$ & $\begin{array}{l}\text { Lab4 data } \\
\text { Standard geometry }\end{array}$ & $\begin{array}{l}\text { Lab2 data } \\
\text { Small geometry 2 }\end{array}$ & $\begin{array}{l}\text { Lab1 data } \\
\text { Small geometry } 1\end{array}$ \\
\hline$\beta_{\text {YS }}$ (Eq. 3) & 0.60 & 0.49 & 0.48 & 0.63 & 0.42 \\
\hline$\beta_{\text {UTS }}$ (Eq. 4a) & 0.09 & 0.09 & -- & 0.11 & 0.10 \\
\hline$\beta_{\text {UTS }}$ (Eq. 4b) & 0.25 & 0.26 & 0.21 & 0.26 & 0.19 \\
\hline
\end{tabular}

The ductile to brittle transition temperatures were estimated by using the total energy up to $u_{m}$ since the uncertainty for the plastic energy is significantly higher (Table 7 to Table 9). The results of the two curve fitting procedure for the temperature dependence of the total energies $\mathrm{E}_{\mathrm{SP}}(\mathrm{T})$ and the corresponding ductile to brittle transition temperatures are given in Table 11 for the standard geometry and in Table 12 for the small geometry. Note however, that even for the tests in liquid nitrogen (at $-196{ }^{\circ} \mathrm{C}$ ) the lower shelf was not reached (cf. Fig. 6).

Table 11: Parameters of the $E_{\text {to }}(T)$ fit, transition temperatures and $\alpha$ coefficients, T91-DEM, standard discs (0.5 mm); based on total energies up to $u_{m}$

\begin{tabular}{lllll}
\hline Parameter & Lab1 & Lab2 & Lab3 & Lab4 \\
& $\varnothing 8 \times 0.5$ & $10 \times 10 \times 0.5$ & $\varnothing 8 \times 0.5$ & $08 \times 0.5$ \\
\hline $\mathrm{A}_{\mathrm{b}}(\mathrm{J})$ & 0.00232 & 0 & 0 & 0 \\
$\mathrm{~B}_{\mathrm{b}}(\mathrm{J})$ & 0.217 & 0.314 & 0.209 & 0.1545 \\
$\mathrm{C}_{\mathrm{b}}(1 / \mathrm{K})$ & 0.0173 & 0.0162 & 0.0225 & 0.0191 \\
$\mathrm{~A}_{\mathrm{d}}(\mathrm{J})$ & 1.292 & 1.382 & 1.560 & 0 \\
$\mathrm{~B}_{\mathrm{d}}(\mathrm{J})$ & 2.347 & 3.290 & 4.311 & 1.7685 \\
$\mathrm{C}_{\mathrm{d}}(1 / \mathrm{K})$ & -0.00478 & -0.00542 & -0.00585 & -0.0074 \\
\hline $\mathrm{T}_{\mathrm{SP}}\left({ }^{\circ} \mathrm{C}\right)$ & -167 & -172 & -178 & -167 \\
\hline$\alpha$ & 0.44 & 0.42 & 0.40 & 0.44 \\
\hline
\end{tabular}

Table 12: Parameters of the $\mathrm{E}_{\mathrm{to}}(\mathrm{T})$ fit, transition temperatures and $\alpha$ coefficients, T91-DEM, small discs (0.25 mm) based on total energies up to $u_{m}$

\begin{tabular}{llll}
\hline Parameter & Lab1 & Lab2 & Lab3 \\
& $\varnothing 3 \times 0.25$ & $3.5 \times 3.50 .25$ & $\varnothing 3 \times 0.25$ \\
\hline $\mathrm{A}_{\mathrm{b}}(\mathrm{J})$ & 0.0115 & 0 & 0 \\
$\mathrm{~B}_{\mathrm{b}}(\mathrm{J})$ & 0.0164 & 0.09630 & 0.01314 \\
$\mathrm{C}_{\mathrm{b}}(1 / \mathrm{K})$ & 0.0208 & 0.005925 & 0.02032 \\
$\mathrm{~A}_{\mathrm{d}}(\mathrm{J})$ & 0.0912 & 0.09893 & 0.06065 \\
$\mathrm{~B}_{\mathrm{d}}(\mathrm{J})$ & 0.1825 & 0.1900 & 0.1960 \\
$\mathrm{C}_{\mathrm{d}}(1 / \mathrm{K})$ & -0.00328 & -0.003767 & -0.00173 \\
\hline $\mathrm{T}_{\mathrm{SP}}\left({ }^{\circ} \mathrm{C}\right)$ & -183 & -193 & -170 \\
\hline$\alpha$ & 0.38 & 0.33 & 0.43 \\
\hline
\end{tabular}

\subsection{Evaluation of the irradiation effect}

Figure 10 shows averaged load-displacement curves for the SP tests at $\mathrm{T}=200{ }^{\circ} \mathrm{C}$. The averaged curve for the unirradiated material was calculated from the tests 34 - 36 (cf. Table 6). For averaging at $3.99 \mathrm{dpa}$, the tests HE07 - HE09 were used and for $2.31 \mathrm{dpa}$ the single measurement MA06 is shown. The radiation effect leads to a reduction of the displacement at maximum load $\mathrm{u}_{\mathrm{m}}$ while the maximum load itself $\left(\mathrm{F}_{\mathrm{m}}\right)$ is not significantly affected. 


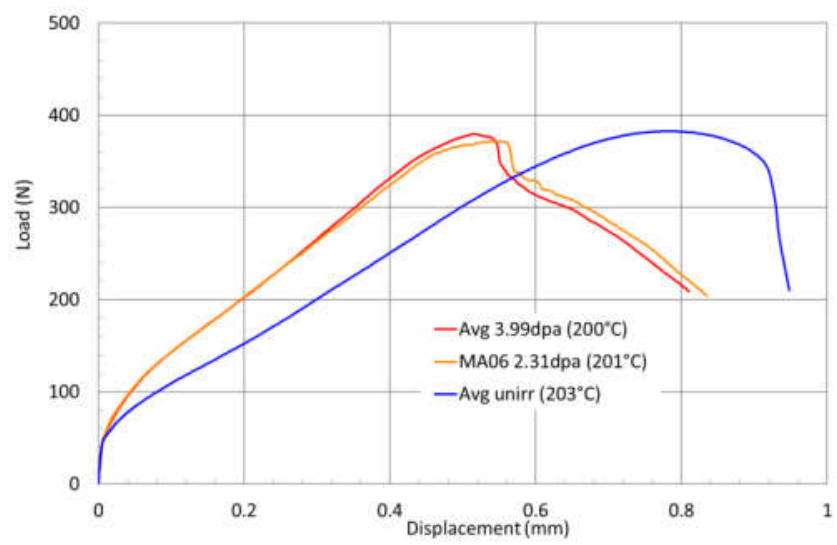

Figure 10: Load-displacement curves at $\mathrm{T}=20{ }^{\circ} \mathrm{C}$ for unirradiated and neutron irradiated T91-SPI, specimen size $4 \times 3 \times 0.3 \mathrm{~mm}$. Averaged curves for unirradiated condition and 3.99 dpa, single measurement MA06 for 2.31 dpa.

The effect of the SP test temperature on $\mathrm{F}_{\mathrm{e}}, \mathrm{F}_{\mathrm{m}}$ and $\mathrm{u}_{\mathrm{m}}$ was analysed for the different irradiation conditions as shown in Figure 11. As already stated above, there is no significant effect of the irradiation on the maximum load $\mathrm{F}_{\mathrm{m}}$. This is true for the whole range of the test temperature. As for the transition load $\mathrm{F}_{\mathrm{e}}$ and the displacement at maximum load $\mathrm{u}_{\mathrm{m}}$, the significance of the irradiation effect depends on the test temperature. A significant increase of $\mathrm{F}_{\mathrm{e}}$ is observed for $\mathrm{T}>-100^{\circ} \mathrm{C}$, whereas a significant decrease of $\mathrm{u}_{\mathrm{m}}$ can be noticed for $\mathrm{T}>0{ }^{\circ} \mathrm{C}$. For lower temperatures, an irradiation effect is either not present or it is covered by the larger scatter of the data.
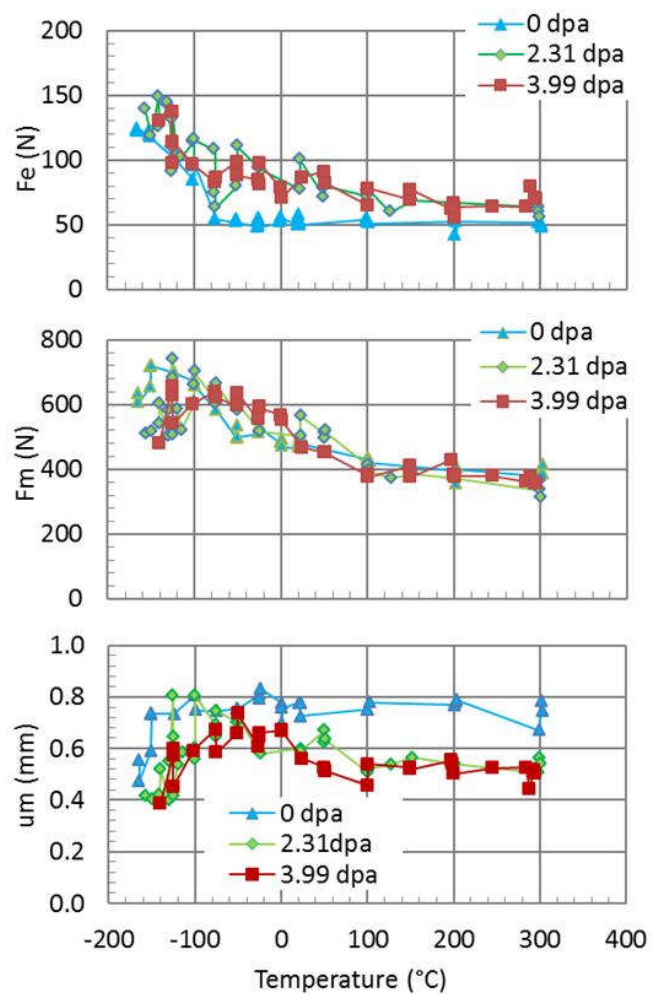

Figure 11: Effect of test temperature and irradiation on: the elastic-plastic transition load $\mathrm{F}_{\mathrm{e}}$ (top), the maximum load $\mathrm{F}_{\mathrm{m}}$ (centre) and displacement at maximum load $\mathrm{u}_{\mathrm{m}}$ (bottom)

The yield stress is estimated from the elastic-plastic transition load $\mathrm{F}_{\mathrm{e}}$ and the initial specimen thickness $h$ using the empirical correlation Eq. (3). The ultimate tensile strength can be estimated from the load-displacement curves either by Eq. (4a) or by Eq. (4b). From Figure 10 it can be concluded that Eq. (4a) would indicate that irradiation has no effect on $R_{m}$ (since 
$\mathrm{F}_{\mathrm{m}}$ is not significantly affected by the neutron dose). This is obviously not the case (cf. Table 3). This speaks for Eq. (4b) being more appropriate.

The pre-factors $\beta_{\text {YS }}$ and $\beta_{\text {UTS }}$ were determined within the collective exercise. For the small geometry (punch diameter $1.0 \mathrm{~mm}$, lower die diameter $1.75 \mathrm{~mm}$ ) values of $\beta_{\mathrm{YS}}=0.63$ and $\beta_{\text {UTS }}=0.26$ were obtained. However, it was also shown that these pre-factors significantly depend on the testing device. As we used a different device for the collective exercise (outside the hot cell lab), a recalculation of these coefficients was necessary. For this we used the SP tests for the unirradiated condition and the tensile data for the unirradiated condition from [17], cf. Figure 2.

Since there is no significant irradiation effect on $\mathrm{F}_{\mathrm{e}}$ and $\mathrm{u}_{\mathrm{m}}$ at low test temperatures (Figure 11) it was decided to use only test data with $\mathrm{T}>0{ }^{\circ} \mathrm{C}$ for the re-calculation of the coefficients $\beta_{Y S}$ and $\beta_{\text {UTS. }}$. The correlations between the YS data from tensile tests (Figure 2) and $F_{e} / h^{2}$ from SP tests and between UTS and $\mathrm{F}_{\mathrm{m}} /\left(\mathrm{h}^{*} \mathrm{u}_{\mathrm{m}}\right)$ respectively were used (cf. section 4.1). The re-calculated coefficients are $\boldsymbol{\beta}_{\mathrm{YS}}=\mathbf{0 . 8 8 4}$ and $\boldsymbol{\beta}_{\mathrm{UTS}}=\mathbf{0 . 3 2 7}$.

These values were used to calculate the tensile properties from the SP tests results by Eq. (3) and Eq. (4b) respectively for all irradiation conditions. As an example, Figure 12 shows the temperature dependent values of the yield stress for $2.31 \mathrm{dpa}$.

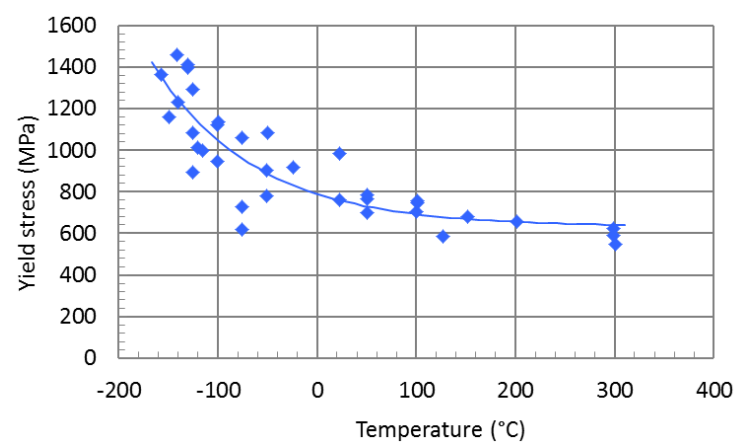

Figure 12: Yield stress vs. temperature obtained from SP tests with fitting curve, T91-SPI, 2.31 dpa

Because of the significant scatter of the data we used an exponential fit to describe the $\mathrm{R}_{\mathrm{p} 02}(\mathrm{~T})$ and $R_{m}(T)$ dependences. The resulting fit equations of the tensile properties obtained from the SP tests are given below.

For the unirradiated condition:

$$
\begin{aligned}
& \mathrm{R}_{\mathrm{p} 02}(\mathrm{MPa})=466+4627 \cdot \exp [-0.0159 \cdot \mathrm{T}(\mathrm{K})] \\
& \mathrm{R}_{\mathrm{m}}(\mathrm{MPa})=564+2204 \cdot \exp [-0.0106 \cdot \mathrm{T}(\mathrm{K})]
\end{aligned}
$$

For the neutron dose 2.31 dpa:

$$
\begin{aligned}
& \mathrm{R}_{\mathrm{p} 02}(\mathrm{MPa})=632+2203 \cdot \exp [-0.010 \cdot \mathrm{T}(\mathrm{K})] \\
& \mathrm{R}_{\mathrm{m}}(\mathrm{MPa})=724+1623 \cdot \exp [-0.0084 \cdot \mathrm{T}(\mathrm{K})]
\end{aligned}
$$

For the neutron dose 3.99 dpa:

$$
\begin{aligned}
& R_{\mathrm{p} 02}(\mathrm{MPa})=664+2172 \cdot \exp [-0.0104 \cdot \mathrm{T}(\mathrm{K})] \\
& \mathrm{R}_{\mathrm{m}}(\mathrm{MPa})=793+1764 \cdot \exp [-0.0093 \cdot \mathrm{T}(\mathrm{K})]
\end{aligned}
$$


The ductile to brittle transition temperature was evaluated from the $\mathrm{E}_{\mathrm{SP}}(\mathrm{T})$ data. The total energy up to the maximum load was used. A two-curve fitting procedure was applied as described in section 3.1. For the neutron dose $2.31 \mathrm{dpa}$ (specimens KR, KS and MA), a SP transition temperature $\mathrm{T}_{\mathrm{SP}}$ of $-148^{\circ} \mathrm{C}$ was obtained. For the dose of $3.99 \mathrm{dpa}$ (specimens HE and $\mathrm{HH}$ ), a SP transition temperature of $-139{ }^{\circ} \mathrm{C}$ was derived (Figure 13).

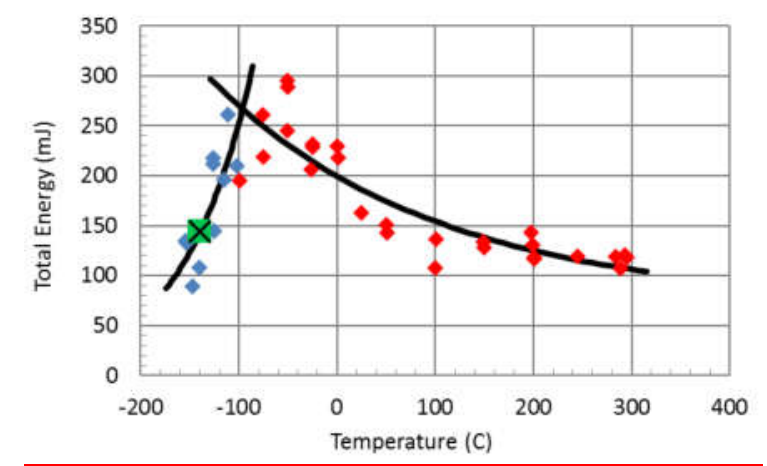

Figure 13: Determination of the DBTT for T91-SPI (3.99 dpa) using the total energy up to $u_{m}\left(T_{S P}=-139{ }^{\circ} \mathrm{C}\right)$

The transition temperature of the unirradiated condition was evaluated to $\mathrm{T}_{\mathrm{SP}}=-174{ }^{\circ} \mathrm{C}$ from tests 01-39. However, the accuracy of this result is considered insufficient because the temperature range of the tests does not provide lower shelf data. The transition temperature is significantly lower than the minimum test temperature. More tests at liquid nitrogen temperature would be needed, but this was not possible in the hot cell.

\section{Discussion}

\subsection{Collective exercise}

The scatter of results (expressed by coefficient of variation $\mathrm{c}_{\mathrm{v}}$ ) for the total and plastic energy $\left(\mathrm{E}_{\mathrm{to}}\right.$ and $\left.\mathrm{E}_{\mathrm{pl}}\right)$, the elastic-plastic transition load $\left(\mathrm{F}_{\mathrm{e}}\right)$, the maximum load $\left(\mathrm{F}_{\mathrm{m}}\right)$ and the displacement at maximum load $\left(\mathrm{u}_{\mathrm{m}}\right)$ was analysed for tests at room temperature and at $300{ }^{\circ} \mathrm{C}$ using the standard geometry (cf. Table 7 and Table 8 ). The best repeatability $\left(\mathrm{c}_{\mathrm{v}}\right.$-values for the individual labs) is obtained for the maximum load $\mathrm{F}_{\mathrm{m}}\left(\mathrm{c}_{\mathrm{v}}=1.3 \% \ldots 3.7 \%\right)$ and for the displacement at maximum load $u_{m}\left(c_{v}=0.9 \% \ldots 2.6 \%\right)$. For these two parameters we also obtained the lowest average $\mathrm{c}_{\mathrm{v}}$-values indicating a minor device dependence. In contrast, we observe quite high values of the lab specific $\mathrm{c}_{\mathrm{v}}$ for $\mathrm{F}_{\mathrm{e}}(1.9 \% \ldots 12.3 \%)$ and $\mathrm{E}_{\mathrm{pl}}$ $(3.1 \% \ldots 13.4 \%)$ and the corresponding $\mathrm{c}_{\mathrm{v}}$ for all labs (up to $22.4 \%$ ) which indicates a less good repeatability and a higher device dependence. In the case of $\mathrm{E}_{\mathrm{pl}}$ this is a consequence of its dependence on the bilinear fit for $\mathrm{F}_{\mathrm{e}}$ (cf. Eq. 8). In general, the average $\mathrm{c}_{\mathrm{v}}$-value are significantly higher than the corresponding lab specific values. Thus, the differences due to the device dependence are more significant than the scatter on one and the same device. Possible reasons for the differences in the load-displacement curves from different devices can be, besides the difference in the diameter and edge radius of lower die hole: i) accuracy of the displacement measurement, ii) deviations of the puncher from the ideal semi-spherical shape, iii) elastic deformation of the puncher, iv) missing or insufficient correction of the displacements for the machine compliance. The comparison of the results of the different geometries shows that the scatter is slightly higher for the small geometry (Table 8 and Table 9).

The rather significant device dependence of $\mathrm{F}_{\mathrm{e}}$ also gives rise to the fact that there is no unitary yield stress coefficient $\beta_{Y S}$ (Table 10). This coefficient depends on the main geometry 
of the SP set-up. However, even in case of identical main geometrical parameters the coefficient seems to be device dependent as shown by the results of Lab1, Lab2 and Lab4 for the standard geometry (Table 10). The coefficient $\beta_{\text {UTS }}$ was not found to be device dependent if the correlation Eq. (4a) is used; all values are between 0.09 and 0.11 . However, it is supposed that Eq. (4a) is not an appropriate correlation for the UTS (cf. sections 4.2 and 5.2). If correlation Eq. (4b) is used the coefficient $\beta_{\mathrm{UTS}}$ is device dependent. Nevertheless, Eq. (4b) is more appropriate than Eq. (4a).

In addition to these findings of the collective exercise it can be supposed that $\beta_{Y S}$ depends also on the hardening behaviour of the material, because the deformation state in the SP specimen is highly non-uniform [13]. The plastic deformation starts in the centre of the disc and proceeds to the peripheral regions. The plastic strain at the load $\mathrm{F}_{\mathrm{e}}$ and displacement $\mathrm{u}_{\mathrm{A}}$ (cf. Figure 4) ranges from 0 to ca. 10\%.This is demonstrated by a finite element simulation of the SP test for the standard geometry at room temperature. Figure 14 shows the load and the plastic strain at two locations as a function of the puncher displacement. The elastic-plastic transition load $\mathrm{F}_{\mathrm{e}}$ evaluated according to Figure 4 is also included.

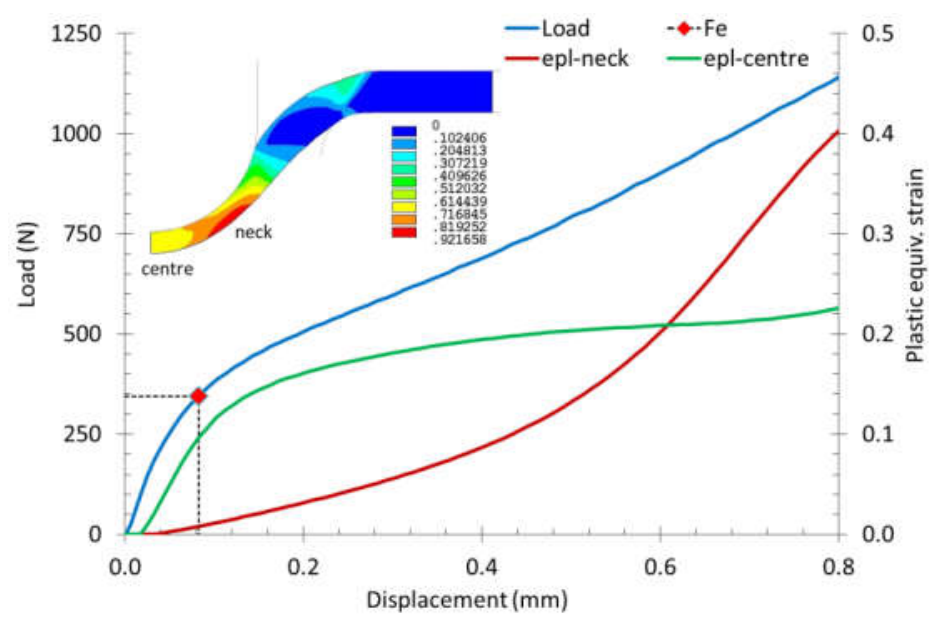

Figure 14: Finite element simulation of the SP test (standard geometry at RT); load and plastic strain as function of puncher displacement; T91-DEM; the insert shows the plastic strain distribution at $\mathbf{u}_{\mathrm{m}}=1.8 \mathrm{~mm}$.

It can be concluded that the maximum plastic strain in the SP sample at load level $\mathrm{F}=\mathrm{F}_{\mathrm{e}}$ is much higher than the value of $0.2 \%$ which corresponds to $R_{p 02}$. Thus, $F_{e}$ (and thereby $\beta_{Y S}$ ) is affected by the work hardening of the material.

For the estimation of the ductile to brittle transition temperature $\mathrm{T}_{\mathrm{SP}}$, the total energy is better suited than the plastic energy. The plastic energies exhibit a significantly larger scatter due to the dependence on $\mathrm{F}_{\mathrm{e}}$ (Eq. 8). For the tests of Lab1 and Lab2, the $\alpha$ values obtained with $0.25 \mathrm{~mm}$ samples are smaller than those obtained with the $0.5 \mathrm{~mm}$ samples. Surprisingly, a slightly higher $\alpha$ value is obtained with the $0.25 \mathrm{~mm}$ samples for the tests of Lab3. It is also interesting to note that the estimated $\mathrm{T}_{\mathrm{SP}}$ values of Lab1 and Lab4 based on $0.5 \mathrm{~mm}$ samples are very close, even though the load-displacement curves are different (Figure 8) and even though the fit parameters are different (Table 11). This speaks for the robustness of the chosen fit procedure. In general, the transition temperature $\mathrm{T}_{\mathrm{SP}}$ decreases with smaller specimen thickness. This implies a need for very low test temperatures for $0.25 \mathrm{~mm}$ specimens in order to have a sufficient number of specimens that fail at low energy. For ductile materials $\left(\mathrm{T}_{\mathrm{CVN}}<-40{ }^{\circ} \mathrm{C}\right)$ it is not always possible to get lower shelf data since usually the lowest possible test temperature is around $-196^{\circ} \mathrm{C}$ (liquid nitrogen). This leads to an uncertainty of the DBTT and might also reduce the inter-laboratory reproducibility. 


\subsection{Irradiation induced hardening and embrittlement}

In Figure 15, the temperature dependent yield strength obtained from the SP tests (section 4.2) is compared with results from tensile tests in the SPIRE project [17]. As there are only two tensile tests available for the irradiated condition from the T91-SPI heat, we included also literature data into the comparison [21]. The curves for the SP data are based on the fit equations given in section 4.2 (Eqs. 10-12).

| For the unirradiated condition (blue tone curves) there is a good agreement of all data for temperatures $\mathrm{T}>0{ }^{\circ} \mathrm{C}$. For low temperatures, the agreement is less good even for the data from tensile tests. The SP based data result in an overestimation of the yield strength in comparison to the values from the tensile tests.

A clear irradiation effect on the yield stress is observed. However, the two tensile tests from the SPIRE project (cf. Table 3) suggest a significantly higher hardening effect than it is obtained from the SP data. Interestingly, the tensile data from [21] show a better agreement with our SP data. Nevertheless it has to be mentioned that the data in [21] are based on a different T91 heat (but with a similar heat treatment) irradiated at $300{ }^{\circ} \mathrm{C}$.

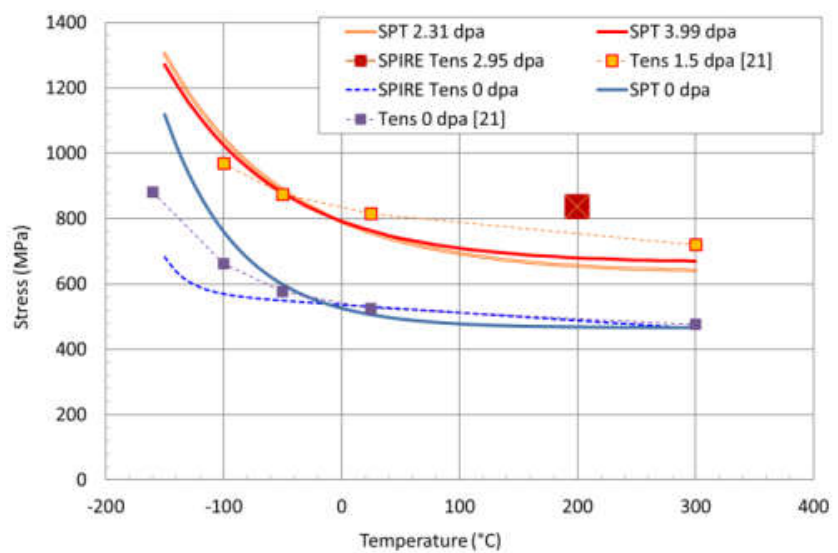

Figure 15: Yield stress vs. temperature of T91 obtained from SP and tensile tests for different neutron doses

Figure 16 shows the corresponding results for the ultimate tensile strength. For the unirradiated condition, the SP based data overestimate the UTS measured in the tensile tests in the range of low temperatures $\left(\mathrm{T}<0{ }^{\circ} \mathrm{C}\right)$ as already observed for the yield strength. The evaluation of the irradiation induced increase of the UTS at $200{ }^{\circ} \mathrm{C}$ agrees well with the tensile test result. 


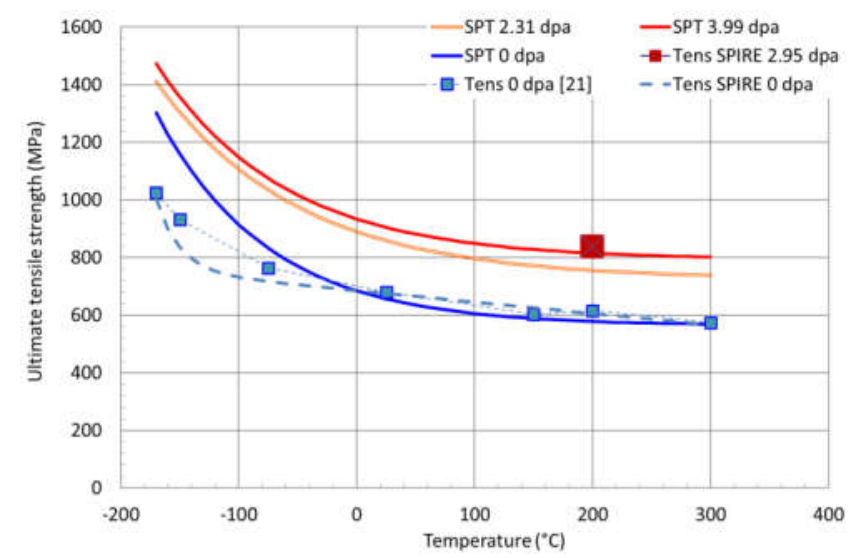

Figure 16: Ultimate tensile strength vs. temperature of T91 obtained from SP and tensile tests for different neutron doses

The distance between the SP based curves of the irradiated condition and the unirradiated reference is decreasing with decreasing temperature (Figure 15 and Figure 16), i.e. a significantly lesser irradiation induced hardening $\left(\Delta \mathrm{R}_{\mathrm{p} 02}\right.$ and $\left.\Delta \mathrm{R}_{\mathrm{m}}\right)$ is indicated at low test temperatures. This is due to the fact that the irradiation effect is not observed in the transition load $\left(\mathrm{F}_{\mathrm{e}}\right)$ and the displacement at maximum load $\left(\mathrm{u}_{\mathrm{m}}\right)$ for low temperatures (Figure 11). Since tensile data for low temperatures are missing for the irradiated condition of T91-SPI, it cannot be decided whether or not there is an irradiation hardening effect at low temperatures.

Anyway, Song et al. demonstrated that irradiation hardening may be overwhelmed by the yield stress increase at low temperatures [22].

The SP transition temperatures can be translated into Charpy transition temperatures by Eq. (1). The conversion factor was determined as $\alpha=0.336$. The translation between the KLST transition temperature and the Charpy transition temperature is given by Eq. (7). In Table 13, the transition temperatures available for the T91-SPI heat are summarized. The comparison of $\mathrm{T}_{\mathrm{SP}}$ and $\mathrm{T}_{\mathrm{KLST}}$ is done via the recalculation of $\mathrm{T}_{\mathrm{CVN}}$ according to the relations above. For the unirradiated condition, the KLST based transition temperature was taken as reference since the SP based value is not trustable-reliable (cf. section 4.2).

Table 13: Ductile to brittle transition temperatures obtained from SP tests and KLST tests [17] and recalculated Charpy transitions
temperatures
\begin{tabular}{lllll}
\hline & measured in MATTER & measured in SPIRE [17] & Recalculated \\
\hline $\mathrm{dpa}$ & $\mathrm{T}_{\mathrm{SP}, 0.3}\left({ }^{\circ} \mathrm{C}\right)$ & $\mathrm{T}_{\mathrm{KLST}}\left({ }^{\circ} \mathrm{C}\right)$ & $\mathrm{T}_{\mathrm{CVN}}\left({ }^{\circ} \mathrm{C}\right)$ & -8 \\
\hline 0 & $(-186)^{1)}$ & -73 & -8 & -- \\
\hline 2.31 & -148 & -- & 100 & 107 \\
\hline 2.43 & -- & 35 & 122 & 108 \\
\hline 3.58 & -- & 57 & 126 & 130 \\
\hline 3.99 & -139 & -- & $\mathrm{T}_{\mathrm{CVN}}(\mathrm{K})$ \\
\hline 1
\end{tabular}

1) Recalculated from $T_{\text {KLST }}$

The recalculated Charpy transition temperature shifts in dependence of the neutron dose are shown in Figure 17. The agreement between the SP based values and the KLST based values | [17] is very good. Hence the SPT-SP test is an appropriate tool for the screening of radiation embrittlement. It should be noted that the SP specimens used to obtain $\mathrm{T}_{\mathrm{SP}}$ for one irradiation condition were manufactured from 2 KLST specimens only, whereas the determination of $\mathrm{T}_{\mathrm{KLST}}$ for one irradiation condition was based on 12 KLST specimens [17]. 


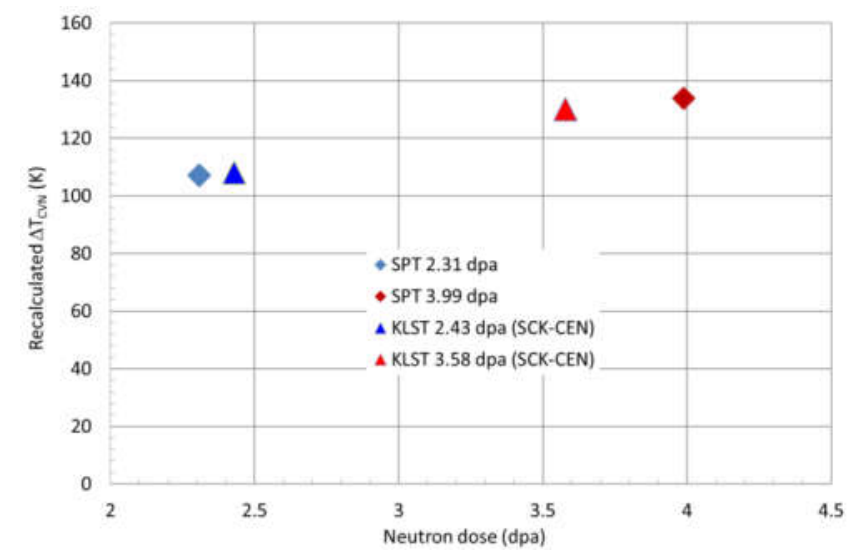

Figure 17: Charpy transition temperature shift $\Delta \mathrm{T}_{\mathrm{CVN}}(\mathrm{K})$, recalculated from SP tests $(4 \times 3 \times 0.3)$ and from KLST tests, vs. neutron dose, T91- SPI

\section{Conclusions}

A small punch test collective exercise was conducted in order to evaluate systematically the scatter and reproducibility of results. Eight groups of data sets for two basic set-up geometries were generated by five participating laboratories.

The relative scatter of results (expressed by coefficient of variation) for the total and plastic energy $\left(\mathrm{E}_{\mathrm{to}}\right.$ and $\left.\mathrm{E}_{\mathrm{pl}}\right)$, the elastic-plastic transition load $\left(\mathrm{F}_{\mathrm{e}}\right)$, the maximum load $\left(\mathrm{F}_{\mathrm{m}}\right)$ and the displacement at maximum load $\left(\mathrm{u}_{\mathrm{m}}\right)$ was analysed for tests at room temperature and at $300{ }^{\circ} \mathrm{C}$.

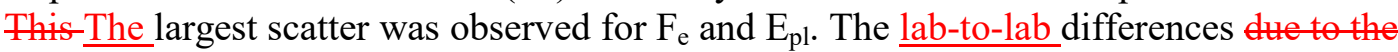
device dependence-are more significant than the scatter of data from one and the same laben ene and the same device. The comparison of the results of the different geometries shows that the scatter is slightly higher for the small geometry. Correlations for the estimation of tensile properties were shown to be device dependent. The estimations of the transition temperatures $\mathrm{T}_{\mathrm{SP}}$ are in a good agreement in cases of identical main geometrical parameters. The total small punch energy up to the maximum load seems to be a good choice for the $\mathrm{E}_{\mathrm{SP}}(\mathrm{T})$ fit.

The irradiation effect is manifested in the load-displacement curves of the small punch test by an increased elastic-plastic transition load $\left(\mathrm{F}_{\mathrm{e}}\right)$ and by a reduced displacement at maximum load $\left(\mathrm{u}_{\mathrm{m}}\right)$. The maximum load $\left(\mathrm{F}_{\mathrm{m}}\right)$ is not significantly affected. For lower test temperatures the irradiation effect on $\mathrm{F}_{\mathrm{e}}$ and $\mathrm{u}_{\mathrm{m}}$ cannot be observed in the SP tests. Since tensile data at lower temperatures for the irradiated material are missing, it could not be decided whether the

| irradiation effect is not present at lower test temperatures or whether it is eovered obscured by the larger scatter of the SP data.

The recalculated Charpy transition temperature shifts obtained from SP tests are in very

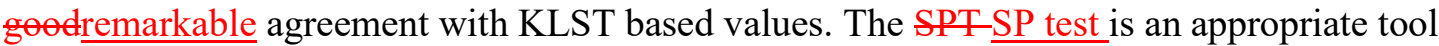
for the screening of the neutron irradiation induced embrittlement in terms of transition temperature shift. Nevertheless it is hardly possible to obtain lower shelf energy data for the unirradiated condition, in particular when small SP discs (thickness $0.25 \mathrm{~mm}$ or $0.3 \mathrm{~mm}$ ) are used instead of standard discs (thickness $0.5 \mathrm{~mm}$ ). Therefore transition temperatures from KLST or even Charpy tests have additionally to be taken into account additionally for the unirradiated condition. In many cases, this does not pose a strong restriction, because the SP test is the method of choice in case of limited availability and/or high activity just of the irradiated material. 
Tensile properties can also be determined from SP test. We observed a significant effect of irradiation on hardening $\left(\mathrm{R}_{\mathrm{p} 02}\right)$. In comparison with tensile data, the irradiation induced hardening was underestimated. It was found to be inevitable, that the SP tests for the unirradiated and for the irradiated conditions have to be performed with one and the same SP device since the conversion factor between the elastic-plastic transition load and the yield strength is strongly device dependent. The correlations for tensile properties (coefficients $\beta_{Y S}$ and $\left.\beta_{\text {UTS }}\right)$ cannot be used for low temperatures $\left(\mathrm{T}<0{ }^{\circ} \mathrm{C}\right)$. All in all the SP test is more appropriate for the screening of embrittlement than it is for hardening.

\section{Acknowledgements}

This work was partly supported by the European community within the FP7 project MATTER under Grant Agreement No. 269706. The authors would also like to express their gratitude to Dr Serguei Gavrilov (SCK•CEN Mol) for the supply of unirradiated and neutron irradiated T91 steels.

\section{References}

[1] G.E. Lucas, Metallurgical Transactions A 21A (1990) 1105-1119

[2] T. Misawa, T. Adachi, M. Saito, Y. Hamaguchi, J. Nucl. Mater. 150 (1987) 194-202.

[3] X. Jia, Y. Dai Y., J. Nucl. Mater. 323 (2003) 360-367.

[4] J.S. Ha, E. Fleury, KSME Int. Journal 12 (1998) 5 818-826

[5] CEN Workshop Agreement CWA 15627: Small Punch Test Method for Metallic Materials. European Committee for Standardization Document CWA 15627:2006 E, 2006

[6] J. McNaney, G.E. Lucas, G.R. Odette, J. Nucl. Mater. 179-181 (1991) 429-433.

[7] M.C. Kim, Y.J. Oh, B.S. Lee: The evaluation of ductile-brittle transition temperature before and after neutron irradiation in RPV steels using a small punch test. Transactions 17th Int. Conf. on Structural Mechanics in Reactor Technology (SMiRT 17), 2003, paper G01-6

[8] J. Kameda, Acta Metallurgica, 34(12), 2391-2398

[9] J. Kameda, X. Mao, J. Material Science 27 (1992) 983-989.

[10] E.N. Campitelli, P. Spaetig, R. Bonade, W. Hoffelner, M. Victoria, J. Nucl. Mater. 335 (2004) 366-378.

[11] K. Matocha, M. Filip, S. Stejskalova, Determination of Critical Temperature of Brittleness $\mathrm{T}_{\mathrm{k} 0}$ by Small Punch Tests, COMAT 2012, , Plzen Czech Republic, 21-22 ${ }^{\text {nd }}$ Nov, 2012

[12] X. Mao, H. Takashi, J. Nucl. Mater. 150 (1987) 42-52.

[13] T.S. Byun, E.H. Lee, J.D. Hunn, K. Farrell, L.K. Mansur, J. Nucl. Mater. 294 (2001) 256-266

[14] M. Abendroth, M. Kuna, Engng. Fract. Mech. 73 (2006) 710-725.

[15] T. Linse, M. Kuna, J. Schuhknecht, H.W. Viehrig, Engng. Fract. Mech. 75 (2008) 3520-3533.

[16] J. van den Bosch, A. Almazouzi, EUROTRANS-DEMETRA Deliverable D4.2: Procurement and Characterisation of T91 and SS316L plates, SCK-CEN report R-4197, July 2005

[17] E. Lucon, A. Almazouzi, Mechanical Response to Irradiation at $200{ }^{\circ} \mathrm{C}$ for EM10, T91 and HT9 - Final Report: Specimens Irradiated to 2.6 and 3.9 dpa, SCK-CEN, Mol, Final Report, SPIRE Project SCK-CEN-BLG-986, 2004.

[18] E. N. Klausnitzer, Materialprüfung, 33 (1991) 5, 132-134

[19] K. Turba, R. Hurst, P. Haehner, Int. J. Pressure Vessels and Piping 111-112(2013) 155161

[20] Y.W. Ma, K.B. Yoon, Materials Science and Engineering A 527 (2010) 3630-3638 
[21] M. Matijasevic, E. Lucon, A. Almazouzi, J. Nucl. Mater. 377 (2008) 101-108

[22] S.-H. Song, R.G. Faulkner, P.E.J. Flewitt, P. Marmy, L.-Q. Wenig, Materials Characterisation 53(2004)1, 35-41 